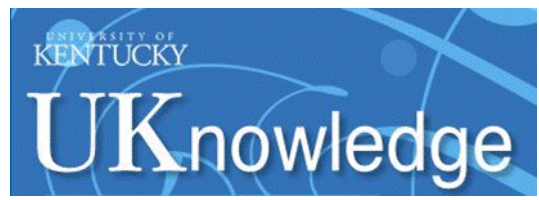

University of Kentucky

UKnowledge

Molecular and Cellular Biochemistry Faculty

Publications

Molecular and Cellular Biochemistry

$2-1-2022$

\title{
PpID Is a De-N-Acetylase of the Cell Wall Linkage Unit of Streptococcal Rhamnopolysaccharides
}

\author{
Jeffrey S. Rush \\ University of Kentucky, jrush@uky.edu \\ Prakash Parajuli \\ University of Kentucky \\ Alessandro Ruda \\ Stockholm University, Sweden \\ Jian Li \\ University of Kentucky, jian.li@uky.edu \\ Amol Arunrao Pohane \\ University of Kentucky
}

Follow this and additional works at: https://uknowledge.uky.edu/biochem_facpub

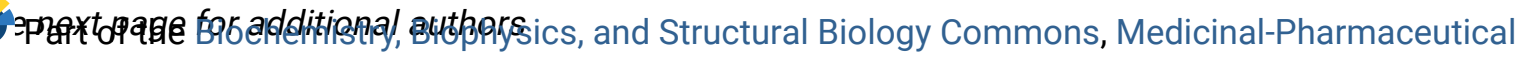
Chemistry Commons, and the Microbiology Commons

Right click to open a feedback form in a new tab to let us know how this document benefits you.

\section{Repository Citation}

Rush, Jeffrey S.; Parajuli, Prakash; Ruda, Alessandro; Li, Jian; Pohane, Amol Arunrao; Zamakhaeva, Svetlana; Rahman, Mohammad M.; Chang, Jennifer C.; Gogos, Artemis; Kenner, Cameron W.; Lambeau, Gérard; Federle, Michael J.; Korotkov, Konstantin V.; Widmalm, Göran; and Korotkova, Natalia, "PpID Is a De-N-Acetylase of the Cell Wall Linkage Unit of Streptococcal Rhamnopolysaccharides" (2022). Molecular and Cellular Biochemistry Faculty Publications. 195.

https://uknowledge.uky.edu/biochem_facpub/195

This Article is brought to you for free and open access by the Molecular and Cellular Biochemistry at UKnowledge. It has been accepted for inclusion in Molecular and Cellular Biochemistry Faculty Publications by an authorized administrator of UKnowledge. For more information, please contact UKnowledge@lsv.uky.edu. 


\title{
PpID Is a De-N-Acetylase of the Cell Wall Linkage Unit of Streptococcal Rhamnopolysaccharides
}

\author{
Digital Object Identifier (DOI) \\ https://doi.org/10.1038/s41467-022-28257-0
}

\section{Notes/Citation Information}

Published in Nature Communications, v. 13, issue 1, article no. 590.

(C) 2022 The Author(s)

This article is licensed under a Creative Commons Attribution 4.0 International License, which permits use, sharing, adaptation, distribution and reproduction in any medium or format, as long as you give appropriate credit to the original author(s) and the source, provide a link to the Creative Commons license, and indicate if changes were made. The images or other third party material in this article are included in the article's Creative Commons license, unless indicated otherwise in a credit line to the material. If material is not included in the article's Creative Commons license and your intended use is not permitted by statutory regulation or exceeds the permitted use, you will need to obtain permission directly from the copyright holder. To view a copy of this license, visit https://creativecommons.org/licenses/by/4.0/.

\section{Authors}

Jeffrey S. Rush, Prakash Parajuli, Alessandro Ruda, Jian Li, Amol Arunrao Pohane, Svetlana Zamakhaeva, Mohammad M. Rahman, Jennifer C. Chang, Artemis Gogos, Cameron W. Kenner, Gérard Lambeau, Michael J. Federle, Konstantin V. Korotkov, Göran Widmalm, and Natalia Korotkova 
ARTICLE

\section{PpID is a de-N-acetylase of the cell wall linkage unit of streptococcal rhamnopolysaccharides}

Jeffrey S. Rush ${ }^{1}$, Prakash Parajuli (i) ${ }^{2}$, Alessandro Ruda (i) ${ }^{3}$, Jian $\mathrm{Li}^{1}$, Amol Arunrao Pohane (i) ${ }^{2}$, Svetlana Zamakhaeva ${ }^{2}$, Mohammad M. Rahman², Jennifer C. Chang (1) ${ }^{4}$, Artemis Gogos (1) 4, Cameron W. Kenner ${ }^{2}$, Gérard Lambeau (1) ${ }^{5}$, Michael J. Federle (id ${ }^{4}$, Konstantin V. Korotkov (i) ${ }^{1}$,

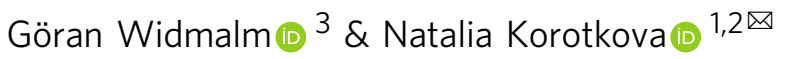

The cell wall of the human bacterial pathogen Group A Streptococcus (GAS) consists of peptidoglycan decorated with the Lancefield group A carbohydrate (GAC). GAC is a promising target for the development of GAS vaccines. In this study, employing chemical, compositional, and NMR methods, we show that GAC is attached to peptidoglycan via glucosamine 1-phosphate. This structural feature makes the GAC-peptidoglycan linkage highly sensitive to cleavage by nitrous acid and resistant to mild acid conditions. Using this characteristic of the GAS cell wall, we identify PpID as a protein required for deacetylation of linkage $\mathrm{N}$-acetylglucosamine (GIcNAc). X-ray structural analysis indicates that PpID performs catalysis via a modified acid/base mechanism. Genetic surveys in silico together with functional analysis indicate that PpID homologs deacetylate the polysaccharide linkage in many streptococcal species. We further demonstrate that introduction of positive charges to the cell wall by GIcNAc deacetylation protects GAS against host cationic antimicrobial proteins.

\footnotetext{
${ }^{1}$ Department of Molecular and Cellular Biochemistry, University of Kentucky, Lexington, KY, USA. ${ }^{2}$ Department of Microbiology, Immunology and Molecular Genetics, University of Kentucky, Lexington, KY, USA. ${ }^{3}$ Department of Organic Chemistry, Arrhenius Laboratory, Stockholm University, Stockholm, Sweden. ${ }^{4}$ Department of Medicinal Chemistry and Pharmacognosy, University of Illinois at Chicago, Chicago, IL, USA. ${ }^{5}$ Université Côte d'Azur, Centre National de la

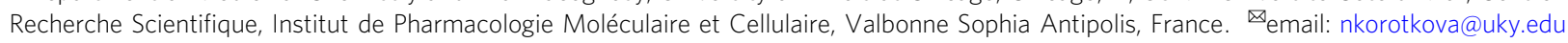


n Gram-positive bacteria, a cell wall outside the plasma membrane determines shape, ensures integrity, and protects the cell from environmental stresses and host immune defense mechanisms. In many streptococci, lactococci, and enterococci, the cell wall consists of multiple layers of peptidoglycan covalently modified with rhamnose (Rha)-containing polysaccharides ${ }^{1}$. These essential polysaccharides are functional homologs of the canonical poly(glycerol-phosphate) and poly(ribitol-phosphate) wall teichoic acids (WTAs) expressed by Bacillus subtilis and Staphylococcus aureus $^{2}$, and non-canonical choline-containing WTAs produced by the Streptococcus mitis group ${ }^{3}$.

Streptococcus pyogenes (Group A Streptococcus, GAS) is a human pathogen of global significance for which a vaccine is not currently available 4 . The key antigenic surface polymer of GAS, the Lancefield group A carbohydrate (GAC), is composed of a repeating $\rightarrow 3) \alpha$-Rha $(1 \rightarrow 2) \alpha$-Rha $(1 \rightarrow$ disaccharide backbone with $N$-acetyl- $\beta$-D-glucosamine (GlcNAc) side-chain modifications attached to the 3 -position of the $\alpha-1,2$-linked Rha ${ }^{5}$. GAC has attracted significant interest from the scientific and medical communities as a vaccine candidate due to its uniform and invariant expression in all GAS serotypes and the absence of the constitutive component of GAC, Rha, in humans ${ }^{6-11}$. Furthermore, in proof-of-principle mouse immunization studies, protein-conjugated GAC vaccines demonstrated efficacy against GAS strains ${ }^{6,7}$. To provide well-defined GAC for immunological studies and vaccine design, knowledge of the structure and biogenesis of GAC is essential ${ }^{9}$. The molecular mechanism of GAC biosynthesis was proposed based on genetic and biochemical studies of two genomic loci encoded by gacABCDEFGHIJKL and $\mathrm{gacO}^{8,12-16}$. GAC biosynthesis is initiated on the inside of the plasma membrane on a lipid carrier, undecaprenyl phosphate (Und-P), by the action of the UDP-GlcNAc:Und-P GlcNAc-1phosphate transferase, GacO. After assembly of the polyrhamnose backbone by the sequential activity of rhamnosyltransferases $\mathrm{GacB}, \mathrm{GacC}$, GacG, and $\mathrm{GacF}$, the nascent polysaccharide is then translocated across the cell membrane via the $\mathrm{ABC}$ transporter GacDE (Supplementary Fig. 1). Enzymatic machinery composed of GacI, GacJ, GacK, and GacL catalyzes the addition of the GlcNAc side-chains, which are then partially decorated with glycerol phosphate (GroP) moieties by $\mathrm{GacH}^{15}$. Finally, the LytRCpsA-Psr (LCP) phosphotransferases transfer GAC from the lipid carrier to peptidoglycan (Fig. 1a). This proposed assembly mechanism is consistent with other isoprenol-mediated polysaccharide biosynthetic pathways in Gram-positive bacteria. The enzymes involved in polyrhamnose biosynthesis and GroP attachment are conserved and organized in similar gene clusters in many streptococci suggesting significant similarities in the structures of streptococcal rhamnopolysaccharides ${ }^{1}$. However, several details of this pathway are still speculative and require further research. Importantly, the chemical structure of the linkage of GAC to peptidoglycan has not been addressed.

In this study, we show that GAC is attached to peptidoglycan via an unexpectedly stable linkage unit. This anomalous behavior is due to the presence of a substantial portion of $\mathrm{N}$-unsubstituted glucosamine $(\mathrm{GlcN})$ in the GAC-peptidoglycan linkage region. We identify PplD, encoded by spy_0818 in the GAS 5005 genome, as the enzyme responsible for deacetylation of GlcNAc in the GAC linker unit. Furthermore, we reveal that deacetylation of the cell wall GlcNAc residues protects GAS from host small cationic antimicrobial proteins (AMPs).

\section{Results}

The GAC-peptidoglycan linkage is resistant to mild acid but sensitive to nitrous acid deamination. GAC was presumed to be covalently linked to peptidoglycan via a GlcNAc phosphodiester to the 6-hydroxyl group of $N$-acetylmuramic acid (MurNAc). This hypothesis is based on the observation that the biosynthetic pathways of GAC, and the S. aureus and B. cereus WTAs share initiating steps catalyzed by $\mathrm{GacO}$ homologs, providing the first sugar residue GlcNAc for the polysaccharide biosynthesis (Supplementary Fig. 1) $2,8,13,17$. In the final steps of peptidoglycan decoration with WTAs, the LCP phosphotransferases attach GlcNAc 1-phosphate to peptidoglycan MurNAc residues forming a GlcNAc phosphodiester bond to peptidoglycan ${ }^{18}$. The WTApeptidoglycan phosphodiester bond is acid labile ${ }^{19}$, and this aspect of the $S$. aureus and B. subtilis cell walls has been used to prepare undegraded, highly-enriched WTAs, freed of peptidoglycan remnants ${ }^{20,21}$. Accordingly, the GAC-peptidoglycan linkage should also be sensitive to these conditions. We subjected purified GAS cell wall and intact sacculi to mild acid conditions $\left(0.02 \mathrm{~N} \mathrm{HCl}, 100^{\circ} \mathrm{C}, 20 \mathrm{~min}\right)$, known to hydrolyze GlcNAc 1phosphate, and measured the release of water-soluble GAC. Surprisingly, these well-established conditions released less than $25 \%$ of GAC from GAS (Fig. 1b, c). The resistance of GAC to release by mild acid hydrolysis suggested the presence of an unacetylated amino sugar in the linkage region as has been reported for Lactobacillus plantarum, which contains a GlcN 1-phosphatelinked WTA. A phosphodiester bond connecting the L. plantarum WTA to peptidoglycan is resistant to mild acid hydrolysis unless first chemically $N$-acetylated ${ }^{20}$. The chemical basis for the extraordinary resistance of GlcN 1-phosphate to acid hydrolysis is illustrated in Supplementary Fig. 2a, b. Hydrolysis of the glycosidic bond of GlcNAc 1-phosphate is facilitated by protonation of the O1-oxygen and subsequent formation of a resonance stabilized oxonium ion intermediate (Supplementary Fig. 2a). However, this reaction is dramatically slowed during incubation of GlcN 1-phosphate under these conditions, because the positively charged GlcN-ammonium group destabilizes the adjacent oxonium ion intermediate (Supplementary Fig. 2b). To test the possibility that a hexosamine residue, devoid of an $\mathrm{N}$-acetyl group, is present in the GAC-peptidoglycan linkage, purified GAS cell wall or sacculi were first chemically $N$-acetylated and then subjected to mild acid hydrolysis. GAC was nearly quantitatively released from peptidoglycan under these conditions, supporting our hypothesis (Fig. 1b, c).

Sugars with primary amino groups, lacking $N$-acetyl groups, undergo deamination by reaction with nitrous acid (HONO). Deamination of polysaccharides containing GlcN residues results in the formation of 2,5-anhydromannose and hydrolysis of the glycosidic bond ${ }^{22}$, as illustrated in Supplementary Fig. 2c. This selective cleavage has been utilized successfully to release the $L$. plantarum WTA from peptidoglycan ${ }^{20}$. Nitrite is rapidly protonated to form HONO in acidic conditions ${ }^{23}$. We observed that incubation of isolated cell wall material and intact sacculi with acidified nitrite released $70-80 \%$ of GAC in a water-soluble form (Fig. 1b, d). In contrast, chemically $N$-acetylated GAS cell wall or sacculi were resistant to this treatment (Fig. 1b, d). Taken together, these results strongly suggest that GAC is attached to peptidoglycan via a hexosamine 1-phosphate linkage.

The GAC-peptidoglycan linkage region contains GlcN and GlcNAc. Our observation that HONO deamination cleaves only $70-80 \%$ of GAC from peptidoglycan, and that treatment with mild acid released $\sim 20-25 \%$ of GAC suggests that GAS produces two classes of rhamnopolysaccharide composed of major and minor fractions containing either hexosamine or $N$-acetylated hexosamine, respectively, in the linkage region. Importantly, mild acid hydrolysis of chemically $N$-acetylated cell wall released GAC nearly quantitatively (Fig. 1b), indicating that failure to achieve complete release of GAC by these treatments was not due to incomplete 
a

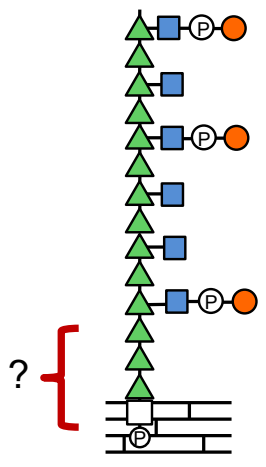

$\triangle$ rhamnose $\square$ GlcNAc

(D) phosphate $\bigcirc$ glycerol b

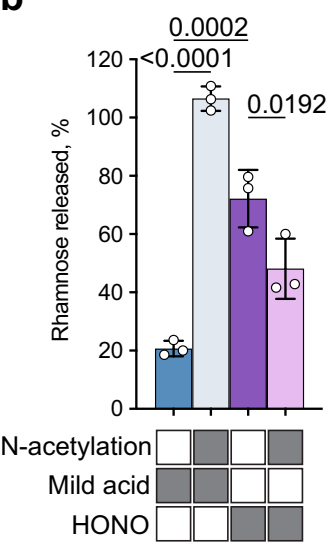

\section{C}

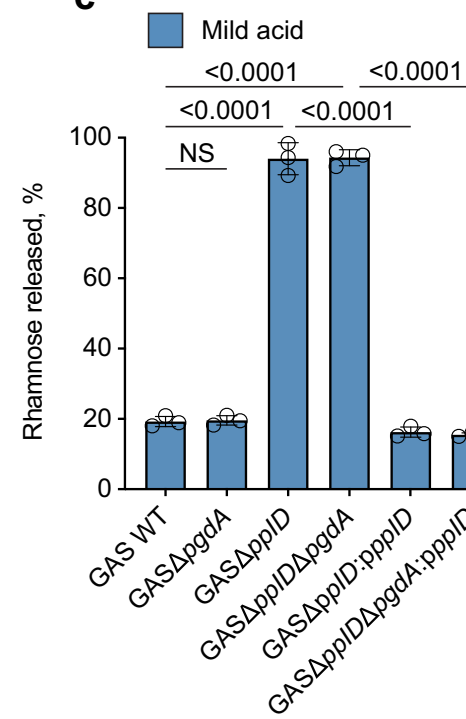

d

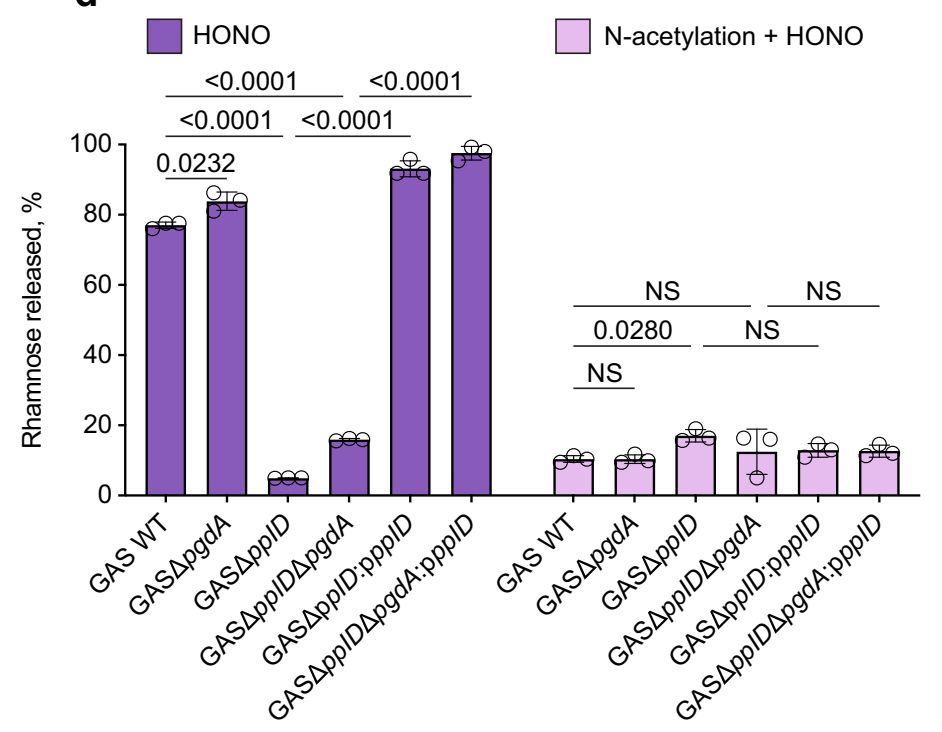

hydrolysis of GAC from peptidoglycan or poor recovery of released material. To verify this conclusion, we sequentially subjected previously deaminated cell walls to mild acid hydrolysis and measured the release of soluble GAC (Supplementary Fig. 3). We observed that the HONO-resistant rhamnopolysaccharide fraction was fully released by the subsequent mild acid treatment. Furthermore, deamination of previously mild acid treated cell walls cleaves the remaining $\sim 80 \%$ of the GAC which is resistant to mild acid hydrolysis (Supplementary Fig. 3).

To identify the hexosamine at the reducing end of the acetylated and un-acetylated forms of GAC, the polysaccharide was released from GAS cell wall by either deamination with 
Fig. 1 Analysis of GAC released from the GAS cell wall by chemical treatments. a Molecular model illustrating GAC covalently attached to peptidoglycan via a phosphodiester bond. GAC contains $a \rightarrow 3) \alpha-R h a(1 \rightarrow 2) \alpha-R h a(1 \rightarrow$ repeating backbone. The $\beta$-GlcNAc side-chains are linked to the 3 position of the $\alpha-1,2$-linked Rha95,96. Phosphate groups in GAC are involved in the phosphodiester bond linking glycerol to the GlcNAc side-chain and the GAC reducing terminal sugar residue to peptidoglycan ${ }^{15}$. b Release of GAC from GAS cell wall by mild acid hydrolysis or HONO deamination, before and after chemical $N$ acetylation. The treatment conditions are indicated by gray rectangles below the bar graph. c Release of GAC from GAS sacculi by mild acid hydrolysis, before (left) and after (right) chemical $\mathrm{N}$-acetylation. $\mathbf{d}$ Release of GAC from GAS sacculi by HONO deamination, before (left) and after (right) chemical $\mathrm{N}$ acetylation. In b-d the concentration of GAC released from the sacculi was estimated by the modified anthrone assay described in "Methods" and normalized to total GAC content in sacculi. Symbols and error bars represent the mean and S.D., respectively $(n=3$ biologically independent replicates). Data are mean values \pm S.D., $n=3$ biologically independent experiments. In $\mathbf{b} P$ values were calculated by one-way ANOVA with Tukey's multiple comparisons test. In $\mathbf{c}, \mathbf{d} P$ values were calculated by two-way ANOVA with Tukey's multiple comparisons test. Source data for $\mathbf{b}$-d are provided as a Source data file.

HONO (nitrous acid sensitive GAC, or GAC ${ }^{\mathrm{NA}}$ ) or mild acid hydrolysis (mild acid sensitive GAC, or GAC ${ }^{\mathrm{MA}}$ ), and reduced chemically with sodium borohydride. Sodium borohydride reduces the aldehyde of 2,5-anhydromannose to form 2,5anhydromannitol and the hemiacetal of GlcNAc to form $\mathrm{N}$ acetyl-D-glucosaminitol (GlcNAcitol). The reduced GACNA and $\mathrm{GAC}^{\mathrm{MA}}$ preparations were then fractionated by size-exclusion chromatography (SEC) on BioGel P150. As confirmed by the composition analysis, both treatments released similar, uniformly-sized polysaccharides eluting near the middle of the column elution volume (Fig. 2a, b). When column fractions were assayed by GC-MS as TMS-methyl glycosides, the GACNA and GAC MA preparations were found to contain Rha and GlcNAc as the only component sugars detected (Fig. 2a, b, upper panels). The reducing-end sugars were detected as alditol acetates by GCMS analysis. This method provides better detection of these minor terminal sugars in the presence of high concentrations of the polymer sugars, Rha and GlcNAc. We identified 2,5anhydromannitol in the GAC ${ }^{\mathrm{NA}}$ preparations, and GlcNAcitol in the GAC ${ }^{\mathrm{MA}}$ preparations (Fig. 2a, b, bottom panels), co-eluting with the peak of carbohydrate, as the only sugar alcohols in these fractions, strongly suggesting that the extracted GAC material contains GlcN and GlcNAc residues as the reducing moiety. Notably, we observed a lower apparent recovery of 2,5anhydromannitol in the HONO-released fraction (Fig. 2b), compared to the recovery of GlcNAcitol in the mild acid released material (Fig. 2a). This result is expected because 2,5-anhydromannitol is not the sole product of deamination of hexosamines ${ }^{22,24}$. In agreement, when we treated commercially available GlcN 1-phosphate with HONO, only $25 \%$ of the expected 2,5-anhydromannitol was recovered (Supplementary Fig. 4).

We have previously shown that GAS and Streptococcus mutans produce rhamnopolysaccharides with variable GroP content, and these forms can be separated by ion-exchange chromatography ${ }^{15,25}$. Further experiments were performed to examine whether the GlcN and GlcNAc linker residues are restricted to a specific ionic isoform of GAC. Fractionation of GACNA and $\mathrm{GAC}^{\mathrm{MA}}$ on DEAE Toyopearl revealed that both polysaccharides contained a similar array of ionic forms: a neutral glycan, not bound to the ionexchange column, and a strongly bound component (Fig. 2c). Similar heterogeneity of GAC was previously observed when the polysaccharide was cleaved from peptidoglycan by the peptidoglycan hydrolases ${ }^{15}$. As expected, the neutral glycan contains very low phosphate content indicating that it has a low degree of GroP modification (Fig. 2c, d). The glycosyl composition of the pooled GAC fractions revealed that the column-bound and unbound fractions from both polysaccharide preparations contain similar Rha/GlcNAc ratio (Fig. 2d). Furthermore, 2,5-anhydromannitol was detected in both the column-bound and unbound fractions of the GAC ${ }^{\mathrm{NA}}$ preparations, and GlcNAcitol in both the columnbound and unbound fractions of the GAC ${ }^{\mathrm{MA}}$ preparations (Fig. 2d).
These observations provide evidence that the GlcN and GlcNAc linker isoforms are not specifically linked to the presence or absence of GroP in GAC and that the only apparent difference in the two populations of GAC is the acetylation status of the linkage GlcN unit.

Chemical structure of the GAC-peptidoglycan linkage region. To elucidate the exact chemical structure of the linkage region, GAC liberated from peptidoglycan by the peptidoglycan hydrolases, PlyC and mutanolysin ${ }^{15}$, was subjected to NMR analysis. As expected from our previous study ${ }^{15}$, when GAC material was analyzed by ${ }^{1} \mathrm{H},{ }^{13} \mathrm{C}-\mathrm{HSQC} \mathrm{NMR}$, the GAC trisaccharide repeating units, $\rightarrow 3)$ - $\alpha$-L-Rhap- $(1 \rightarrow 2)[\beta$-D-GlcpNAc- $(1 \rightarrow 3)]$ - $\alpha$-LRha $p-(1 \rightarrow$, were observed at highest level of intensity. The polysaccharide decorated by $s n$-Gro-1-phosphate groups as substituents at $\mathrm{O} 6$ of the side-chain D-Glc $p$ NAc residues were identified at the second intensity level of NMR spectra ${ }^{15}$. To unravel how GAC is linked to peptidoglycan, the analysis was performed at the third level of intensity in the NMR spectra. In the ${ }^{31} \mathrm{P}$ NMR spectrum of GAC, a resonance was observed at $-1.35 \mathrm{ppm}$, having a chemical shift characteristic of a phosphodiester $^{26}$. From ${ }^{1} \mathrm{H},{ }^{31} \mathrm{P}$-Hetero-TOCSY experiments ${ }^{27}$ correlations may be detected from the ${ }^{31} \mathrm{P}$ nucleus to protons of adjacent residues and in the spectrum with a mixing time of $50 \mathrm{~ms}$ cross-peaks were observed to protons of a methylene group, $\delta_{\mathrm{H}} 4.10$ and 4.19 , identified in a multiplicity-edited ${ }^{1} \mathrm{H},{ }^{13} \mathrm{C}$-HSQC spectrum $\left(\delta_{\mathrm{C} 6} 64.3\right)$ (Fig. 3); these correlations were confirmed via ${ }^{1} \mathrm{H},{ }^{31} \mathrm{P}-\mathrm{HMBC}$ experiments. A longer mixing time of $80 \mathrm{~ms}$ in the ${ }^{1} \mathrm{H},{ }^{31} \mathrm{P}-\mathrm{HMBC}$ experiment and analysis of ${ }^{1} \mathrm{H},{ }^{1} \mathrm{H}$-TOCSY spectra for which mixing times up to $120 \mathrm{~ms}$ were used in conjunction with ${ }^{1} \mathrm{H},{ }^{13} \mathrm{C}$-HSQC, ${ }^{1} \mathrm{H},{ }^{13} \mathrm{C}$-HSQC-TOCSY and $2 \mathrm{D}{ }^{1} \mathrm{H},{ }^{1} \mathrm{H}$-NOESY spectra, complemented by NMR chemical shift predictions made by the CASPER program, ${ }^{28}$ facilitated identification of a hexopyranoside $\left(\delta_{\mathrm{C} 1} 102.4\right)$ spin-system having the gluco-configuration. Importantly, in the ${ }^{1} \mathrm{H},{ }^{13} \mathrm{C}-\mathrm{HMBC}$ spectrum a correlation was observed between $\delta_{\mathrm{Ha}} 4.36$ of a lactyl group and $\delta_{\mathrm{C} 3} 80.2$ of the hexopyranoside residue and in a ${ }^{1} \mathrm{H},{ }^{1} \mathrm{H}$-NOESY spectrum connectivity between entities was further substantiated by a cross-peak at $\delta_{\mathrm{Ha}} 4.36 / \delta_{\mathrm{H} 3} 3.63$ thereby identifying the sugar having $\delta_{\mathrm{C} 4} 75.7$ and ${ }^{1} J_{\mathrm{C} 1, \mathrm{H} 1} 167 \mathrm{~Hz}$ as a $\beta$ MurNAc residue being part of a peptidoglycan chain (Supplementary Table 1). The ${ }^{13} \mathrm{C}$ NMR resonance assigned to $\mathrm{C} 5$ of the MurNAc residue showed ${ }^{3} J_{\mathrm{C} 5, \mathrm{P}} 7.6 \mathrm{~Hz}$, fully consistent with a phosphodiester 6-O-substitution ${ }^{29}$. The spectral data of nuclei in the hexopyranose ring are consistent with previously reported NMR chemical shift assignments of an oligomeric form of peptidoglycan structures ${ }^{30}$.

The ${ }^{1} \mathrm{H},{ }^{31} \mathrm{P}$-Hetero-TOCSY spectra employing a mixing time of $50 \mathrm{~ms}$ also showed correlations from ${ }^{31} \mathrm{P}$ to a proton at $\delta_{\mathrm{H} 1}$ 5.54 and with a longer mixing time of $80 \mathrm{~ms}$ a cross-peak was identified at $\delta_{\mathrm{H} 2} 2.89$ (Fig. 3); these correlations were confirmed 

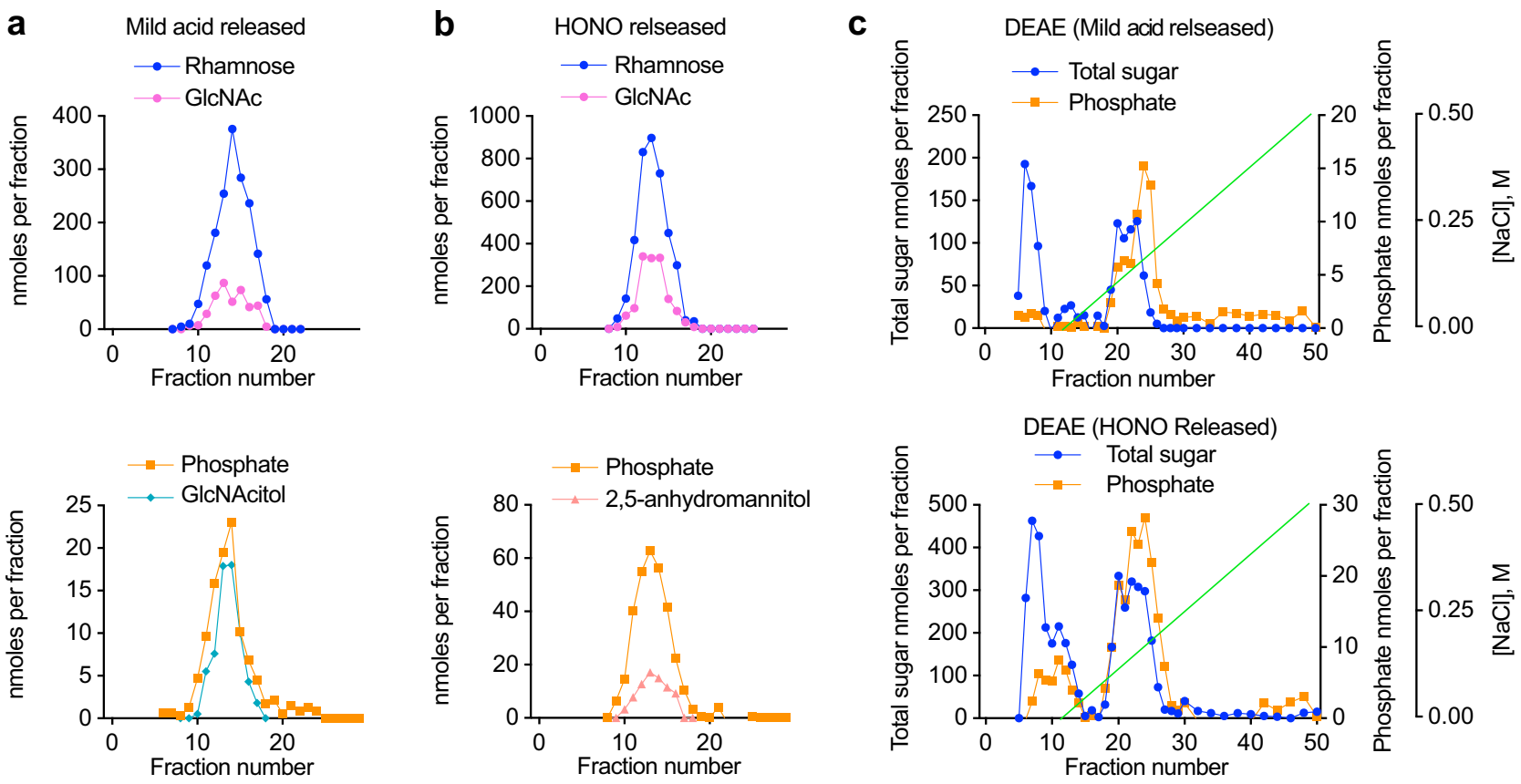

d

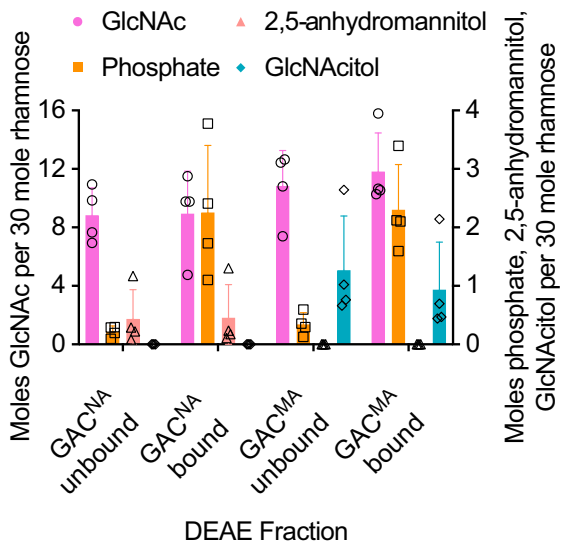

Fig. 2 Glycosyl composition analysis of GAC released from cell wall by the chemical treatments and purified by size-exclusion and ion-exchange chromatography. a Size-exclusion chromatography of GAC released from GAS cell wall by mild acid hydrolysis or b deamination with HONO. Upper and lower panels show the composition of the BioGel P150 fractions of the individual GAC preparations. Prior to the chromatography, the extracted GAC material was reduced chemically with sodium borohydride. Fractions were analyzed for phosphate content by malachite green assay following digestion with perchloric acid. Rha and GIcNAc contents were measured by GC-MS as TMS-methyl-glycosides. GlcNAcitol and 2,5-anhydromannitol contents were estimated by GC-MS as alditol acetates. The chromatographic profiles are representative of more than three separate experiments. $\mathbf{c}$ lon-exchange chromatography of GAC released from the GAS cell wall by mild acid (upper panel) and HONO (lower panel). Fractions containing the GAC material from (a, b) were pooled, concentrated, desalted by spin column, loaded onto DEAE-Toyopearl and eluted with a $\mathrm{NaCl}$ gradient (0-0.5 M). Fractions were analyzed for total sugar content by anthrone assay and total phosphate content by malachite green assay following perchloric acid digestion. The experiments were performed at least three times and yielded the same results. Data from one representative experiment are shown. d Glycosyl composition analysis of the GAC material purified by ion-exchange chromatography. The GAC material released by either deamination with HONO $\left(G^{N} C^{N A}\right.$ ) or mild acid hydrolysis (GACMA) was analyzed as shown in (c). Fractions unbound (flow-through) and bound (eluted with a $\mathrm{NaCl}$ gradient) to the DEAE column were pooled, concentrated, desalted by spin column and analyzed by GC-MS to determine the Rha, GlcNAc, 2,5-anhydromannitol and GlcNAcitol concentrations as described above. Malachite green assay was used to assay the phosphate concentration. The concentrations of GlcNAc, 2,5anhydromannitol, GlcNAcitol and phosphate are expressed as moles per 30 moles of Rha. Columns and error bars represent the mean and S.D., respectively ( $n=4$ biologically independent replicates). Source data are provided as a Source data file.

in a ${ }^{1} \mathrm{H},{ }^{31} \mathrm{P}-\mathrm{HMBC}$ spectrum. The combined analysis of ${ }^{1} \mathrm{H},{ }^{1} \mathrm{H}$-TOCSY and ${ }^{1} \mathrm{H},{ }^{13} \mathrm{C}-\mathrm{HSQC}$ spectra indicated that the spin-system originates from a hexopyranoside residue $\left(\delta_{\mathrm{C} 1} 96.5\right)$ having the gluco-configuration with an $\alpha$-anomeric configuration $\left({ }^{1} J_{\mathrm{C} 1, \mathrm{H} 1} 177 \mathrm{~Hz}\right)$ as part of a phosphodiester linkage ${ }^{31,32}$. The ${ }^{13} \mathrm{C}$ NMR chemical shift $\delta_{\mathrm{C} 2} 56.0$ is indicative of a nitrogen-carrying carbon suggesting that this residue is the primer of the $\mathrm{GAC}^{16}$. However, the ${ }^{1} \mathrm{H}$ NMR chemical shift $\delta_{\mathrm{H} 2} 2.89$ at $\mathrm{pD} \sim 8$ is conspicuously low and was pD-dependent, which supports that the D-GlcN residue is devoid of an $N$-acetyl group ${ }^{33-35}$ Furthermore, a $\beta$-L-Rhap residue was identified by ${ }^{1} J_{\mathrm{C} 1, \mathrm{H} 1}$ $163 \mathrm{~Hz}$ and intra-residue cross-peaks in a ${ }^{1} \mathrm{H},{ }^{1} \mathrm{H}$-NOESY spectrum from $\mathrm{H} 1$ to $\mathrm{H} 2, \mathrm{H} 3$, and $\mathrm{H} 5$. The ${ }^{13} \mathrm{C}$ NMR chemical 


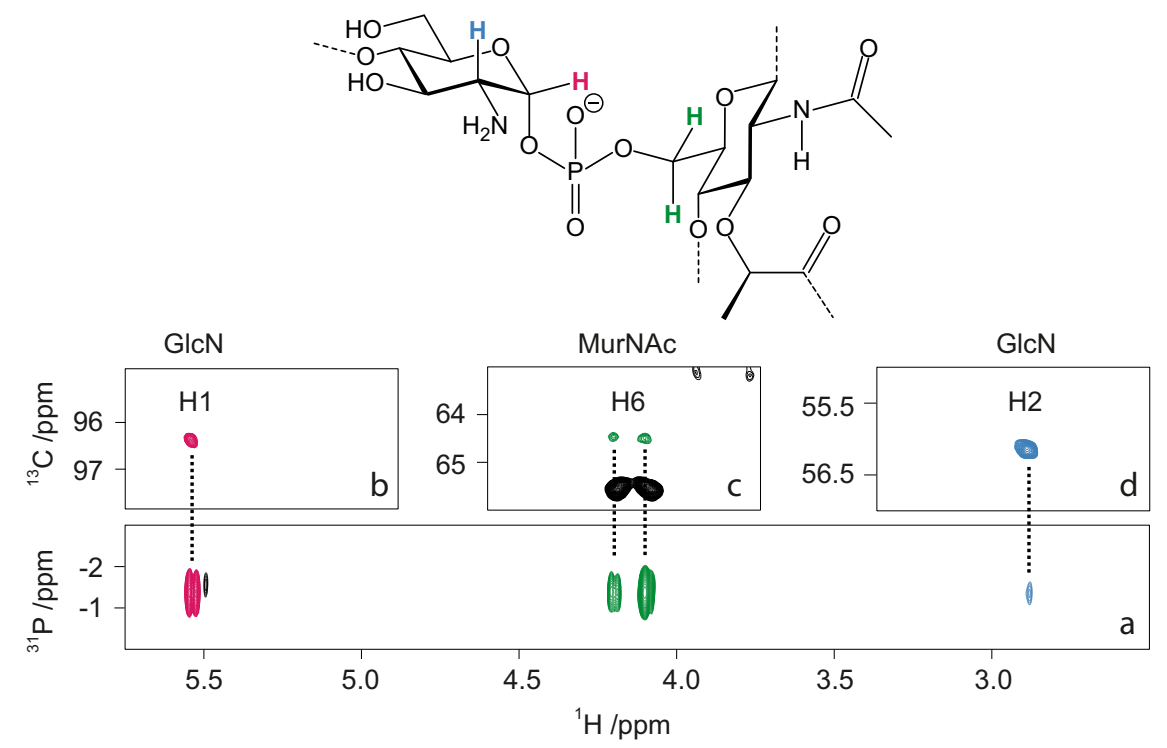

Fig. 3 Chemical structure of the GAC-peptidoglycan linkage region determined by NMR analysis. Representative structure of the linkage region of GAC anchored to the peptidoglycan layer (top). ${ }^{1} \mathrm{H}, 31 \mathrm{P}-\mathrm{HMBC}$ NMR spectrum (a) with a $90 \mathrm{~ms}$ delay for the evolution of long-range $J$ couplings shows the key correlation between proton $\mathrm{H} 1(\mathbf{b})$ and $\mathrm{H} 2(\mathbf{d})$ of $\mathrm{GlcN}$, and the two protons in position 6 of MurNAc (c) to a unique ${ }^{31} \mathrm{P}$ signal at $-1.35 \mathrm{ppm}$, characteristic of a phosphodiester linkage between the two residues. b-d Show the corresponding signals in the multiplicity-edited ${ }^{1} \mathrm{H},{ }^{13} \mathrm{C}-\mathrm{HSQC}$ NMR spectrum. The two H6 signals of MurNAc were observed in opposite phase due to the multiplicity selection.

shift of $\mathrm{C} 3$ at $\delta_{\mathrm{C} 3} 81.4$ in the $\beta$-L-Rhap residue (Supplementary Table 1) is higher by $7.6 \mathrm{ppm}$ compared to that of the monosaccharide ${ }^{36}$, suggesting that it is substituted by a sugar residue at $\mathrm{O} 3^{37}$. The priming $\mathrm{D}-\mathrm{GlcN}$ residue is substituted at $\mathrm{O} 4$ by the $\beta$-L-Rha $p$ residue as seen from a ${ }^{1} \mathrm{H},{ }^{13} \mathrm{C}$-HMBC correlation $\delta_{\mathrm{H} 1} 4.89 / \delta_{\mathrm{C} 4} 77.7$ and in a ${ }^{1} \mathrm{H},{ }^{1} \mathrm{H}$-NOESY spectrum with a crosspeak at $\delta_{\mathrm{H} 1} 4.89 / \delta_{\mathrm{H} 4} 3.69$, consistent with a $\beta$-L-Rhap- $(1 \rightarrow 4)$ - $\alpha$ $\mathrm{D}-\mathrm{Gl} c \mathrm{pN}$ disaccharide, derived from transfer of $\mathrm{L}-\mathrm{Rh}$ from TDP$\beta$-L-Rha onto the acceptor GlcNAc-PP-Und catalyzed by GacB ${ }^{16}$ (Supplementary Fig. 1). Taken together, the results from the NMR analysis show that GAC is attached by its primer D-GlcN via a phosphodiester linkage to MurNAc of the peptidoglycan.

The newly synthesized cell wall is decorated with GlcNAc 1phosphate-linked GAC. In Gram-positive bacteria, the cell wall polysaccharides conceal peptidoglycan from molecular interactions with proteins ${ }^{25,38}$. We reasoned that since the chemical treatments of GAS sacculi cleave a specific form of GAC possessing either the GlcN or GlcNAc residues in the GACpeptidoglycan linkage, these treatments might reveal surface peptidoglycan regions expressing the pertinent modification by following peptidoglycan-specific protein binding. Thus, to examine the cellular localization of these specific GAC forms, we generated a fluorescent molecular tool with tight binding to peptidoglycan. We constructed a protein fusion, GFP-AtlA $\mathrm{Efs}^{\mathrm{fs}}$, in which the C-terminal cell wall-binding domain of the Enterococcus faecalis major cell division autolysin $\mathrm{Atl}^{39,40}$ is fused at the N-terminus with a green fluorescent protein (GFP) (Supplementary Fig. 5). This cell wall-binding domain consists of six LysM repeats (Pfam PF01476) that recognize peptidoglycan ${ }^{41}$. The protein fusion was added exogenously to the GAS sacculi subjected to either no treatment, mild acid hydrolysis, or deamination. Fluorescence microscopy imaging revealed that the protein fusion did not associate with the majority of untreated sacculi (Fig. 4 and Supplementary Table 2). In contrast, the sacculi treated with $\mathrm{HONO}$ demonstrated uniform distribution of GFP-AtlA ${ }^{\mathrm{Efs}}$ over the cell surface (Fig. 4). Interestingly, the majority of sacculi subjected to mild acid hydrolysis were stained by GFP-AtlA ${ }^{\mathrm{Efs}}$ in the regions of active cell division: septal regions and newly formed

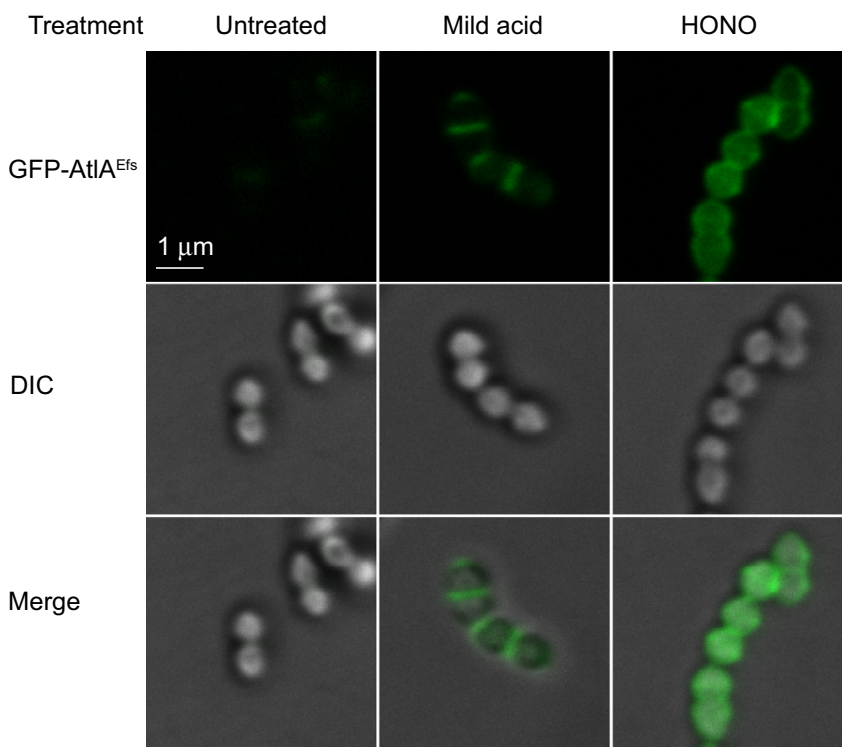

Fig. 4 Binding of GFP-AtIA Efs to GAS sacculi. Intact sacculi (untreated), sacculi subjected to mild acid hydrolysis (mild acid), or deamination with HONO (HONO) were incubated with GFP-AtIAEfs, and examined by fluorescence microscopy (GFP-AtIAEfs, top panels) and differential interference contrast (DIC, middle panels). An overlay of fluorescence and DIC (merge) is shown in the bottom panels. The experiments were performed independently three times and yielded the same results. Representative image from one experiment is shown. Scale bar is $1 \mu \mathrm{m}$.

poles (Fig. 4 and Supplementary Table 2). This observation indicates that i) the chemical treatments do not lead to degradation of the peptidoglycan sacculi; and ii) the regions of active cell division contain the GlcNAc 1-phosphate-linked GAC. These zones correspond to the newly synthesized cell wall.

PplD deacetylates the GAC-peptidoglycan linkage region. Our observation that a substantial fraction of the GAC-peptidoglycan 
linkage region carries a GlcN residue suggests enzymatic deacetylation of GlcNAc as an undescribed step in GAC biosynthesis. The GAS genome encodes two proteins, PgdA and Pdi, annotated as putative GlcNAc deacetylases. PgdA is a homolog of the peptidoglycan GlcNAc N-deacetylase from Streptococcus pneumoniae $^{42}$. Pdi was originally identified in the fish pathogen Streptococcus iniae ${ }^{43}$. While the function of this protein has not been described, it was named Pdi for polysaccharide deacetylase of $S$. iniae. We renamed this protein to PplD (polysaccharidepeptidoglycan linkage deacetylase) for the reasons provided below. To examine the functions of PplD and PgdA in deacetylation of the GAC linker region, we generated $p p l D$ and $p g d A$ single deletion mutants and the double deletion mutant in a GAS NZ131 strain, creating GAS $\triangle p p l D$, GAS $\triangle p g d A$, and GAS $\Delta p p l D \Delta p g d A$, respectively. Since the chemical treatments produced similar results with the GAS cell wall and sacculi (Fig. 1b-d), for convenience we used the sacculi of the constructed strains to test the sensitivity of the phosphodiester linkage to mild acid and HONO treatment. Mild acid hydrolysis liberated the polysaccharide almost quantitatively from the GAS $\Delta p p l D$ and GAS $\Delta p p l D \Delta p g d A$ sacculi (Fig. 1c). Conversely, the sacculi of these mutants were almost completely resistant to deaminative cleavage with HONO (Fig. 1d). Moreover, chemical $N$-acetylation of the GAS $\triangle p p l D$ and GAS $\triangle p p l D \Delta p g d A$ sacculi prior to the treatments with either mild acid or HONO did not significantly affect the release of GAC (Fig. 1c, d). In contrast, the GAS $\triangle p g d A$ sacculi behaved in these assays like the WT control (Fig. 1c, d). These data indicate that PplD is required for deacetylation of the GAC-peptidoglycan linker region.

PplD structure. PplD is predicted to contain an N-terminal transmembrane helix and an extracellular catalytic domain (ePplD) connected by a linker region. To facilitate the functional analysis of PplD, we solved the crystal structure of ePplD (residues $94-320$ ) to $1.78 \AA$ resolution (Supplementary Table 3). There were two molecules in the asymmetric unit that are very similar to each other with a r.m.s.d. of $0.3 \AA$ over 226 aligned Ca atoms. Analysis of the crystal contacts revealed that the dimer interface is the largest with $632 \AA^{2}$ buried surface area that scored below the stable complex formation criteria ${ }^{44}$. In addition, ePplD behaves as a monomer in solution according to SEC. The structure of ePplD revealed a $(\beta / \alpha)_{7}$-barrel fold that is characteristic of carbohydrate esterases of the CE4 family (Fig. 5a). The analysis of the putative active site revealed the presence of a metal ion, which we identified as $\mathrm{Zn}^{2+}$ based on analysis of anomalous difference maps and temperature factors of the ion and coordinating atoms. The $\mathrm{Zn}^{2+}$ ion is coordinated by the side chains of residues D168, H223, and H227 (Fig. 5b). This coordination pattern of the D-H$\mathrm{H}$ residues is common for the metal coordination in CE4 family members. An additional electron density observed next to the $\mathrm{Zn}^{2+}$ ion was assigned as acetate, one of the products of the deacetylation reaction. The compound makes a bi-dentate contact with the $\mathrm{Zn}^{2+}$ ion. Altogether, the side chains of D168, H223, and $\mathrm{H} 227$, acetate and a water molecule complete an octahedral coordination of the $\mathrm{Zn}^{2+}$ ion (Fig. 5b). One of the oxygen atoms of acetate makes a hydrogen bond with the backbone amide of S264, an oxyanion hole, while another oxygen atom of acetate forms a hydrogen bond with catalytic residue H105. A semiburied D167, which is likely involved in coordination of a catalytic water molecule, makes a bi-dentate salt bridge with R302 and an additional hydrogen bond with N191. Altogether, the structural features of ePplD are consistent with the deacetylase function of this enzyme.

The structural comparison of PplD with the available protein structures shows that this enzyme is more distantly related to $S$. pneumoniae PgdA ${ }^{45}$, but similar to the exopolysaccharide poly$N$-acetylglucosamine (PNAG) deacetylases PgaB and IcaB produced by Escherichia coli and Ammonifex degensii, respectively (Supplementary Table 4$)^{46,47}$. The core of the catalytic domains of PplD and PgdA is similar with a r.m.s.d. of $2.4 \AA$ over $140 \mathrm{C} a$ atoms. However, the $\mathrm{N}$ - and C-termini are swapped and located on the opposite ends of $\beta / \alpha$ barrel (Supplementary Fig. 6). Moreover, in comparison to canonical members of the CE4 protein family, PplD displays differences in the MT1-MT5 sequence motifs. While, the MT1, MT2, and MT5 motifs containing the catalytic residues and the residues coordinating $\mathrm{Zn}^{2+}$ ion are conserved in PplD and PgdA (Supplementary Fig. 6), PplD lacks the MT4 motif that carries an aspartic acid residue involved in activation of the catalytic histidine (H105 in PplD). Additionally, the MT3 motif of PplD lacks an arginine residue that coordinates a catalytic aspartic acid residue (D167 in PplD). Instead, D167 is coordinated by R302 located at a different position in the sequence. These sequence deviations from canonical CE4 hydrolases are also present in E. coli PgaB and A. degensii IcaB.

To functionally assess the requirement of the presumed catalytic residues of PplD, we complemented GAS $\triangle p p l D$ and GAS $\Delta p p l D \Delta p g d A$ with WT $p p l D$ expressed on a plasmid creating the GAS $\Delta p p l D: p p p l D$ and GAS $\Delta p p l D \Delta p g d A: p p p l D$ strains, and GAS $\triangle p p l D$ with catalytically inactive versions of pplD in which the active site residues H105 and D167, were replaced by alanine and asparagine, respectively, creating GAS $\triangle p p l D: p p p l D-H 105 A, \quad$ GAS $\triangle p p l D: p p p l D-D 167 N$, and GAS $\triangle p p l D: p p p l D-H 105 A / D 167 N$. Complementation of the mutants by expression of the WT $p p l D$ completely restored the phenotype of the mutants (Figs. $1 \mathrm{c}, \mathrm{d}, 5 \mathrm{c}$ ). Importantly, in GAS $\triangle p p l D: p p p l D$ and GAS $\Delta p p l D \Delta p g d A: p p p l D$, the phosphodiester GAC-peptidoglycan bond was significantly more sensitive to deaminative cleavage by HONO than in the WT (Figs. 1d and 5c). This result indicates that the plasmid expression of PplD in GAS provided the cells with fully deacetylated GAC linker region. In contrast, the GAS $\triangle p p l D: p p p l D-H 105 A, \quad$ GAS $\triangle p p l D: p p p l D-D 167 N$, and GAS $\triangle p p l D: p p p l D-H 105 A / D 167 N$ mutants behaved similarly to GAS $\triangle p p l D$ (Fig. 5c). Thus, based on the functional requirement of $\mathrm{H} 105$ and $\mathrm{D} 167$ for catalysis and the structural features of the active site, we propose that PplD functions via an alternative enzymatic mechanism similar to $A$. degensii $\mathrm{IcaB}^{47}$. In this mechanism, the hydrolysis of the GlcNAc moiety would occur via a water molecule coordinated by $\mathrm{Zn}^{2+}$ ion and D167 (Fig. 5d). The nucleophilic attack on the $N$-acetyl group of the GlcNAc residue would be initiated by deprotonation of the catalytic water molecule by H105. The resulting tetrahedral oxyanion intermediate would be coordinated by the $\mathrm{Zn}^{2+}$ ion and the backbone amide of S264 acting as an oxyanion hole. The protonation of the nitrogen of the intermediate by $\mathrm{H} 105$ in the histidinium form would lead to hydrolysis and generation of the GlcN moiety and a free acetate. In this mechanism, $\mathrm{H} 105$ would serve as a bifunctional catalytic base/acid of the reaction.

Modulation of the cell wall net charge by PplD, PgdA, and $\mathrm{GacH}$ affects resistance to AMPs. In a number of bacteria, PgdA protects bacteria from host AMP, lysozyme, by deacetylating the peptidoglycan GlcNAc residues ${ }^{42,48-50}$. Lysozyme catalyzes the breakdown of $\beta$ - $(1,4)$ linkages between the MurNAc and GlcNAc saccharides leading to peptidoglycan hydrolysis and bacterial lysis ${ }^{51}$. In addition to $N$-acetylmuramidase activity, lysozyme kills bacteria by a non-enzymatic mechanism ${ }^{52}$. This mechanism is similar to killing by small cationic peptides ${ }^{53}$, and is attributed to 
a
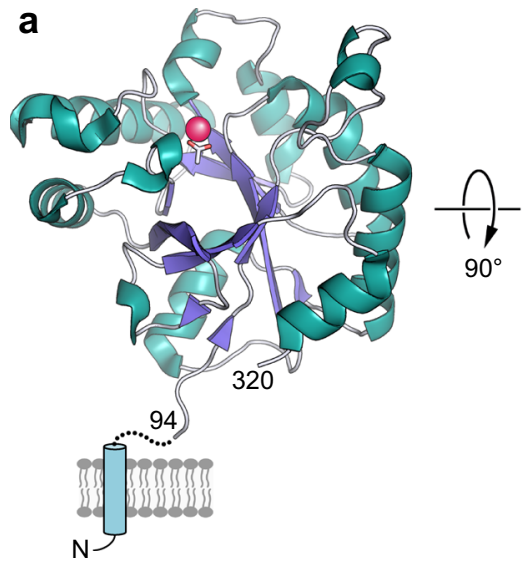

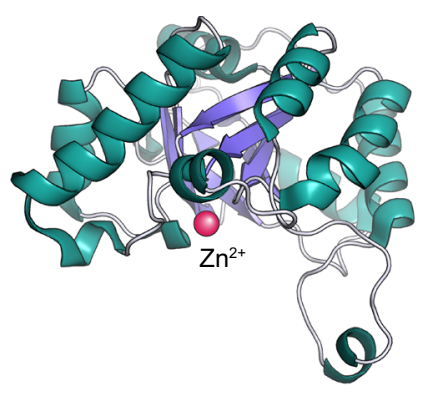

b

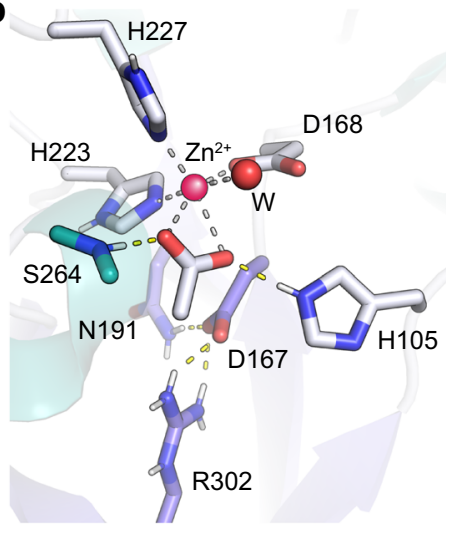

C

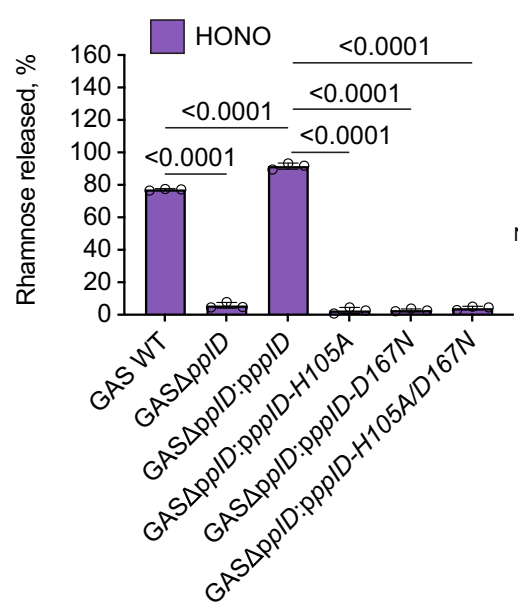

d

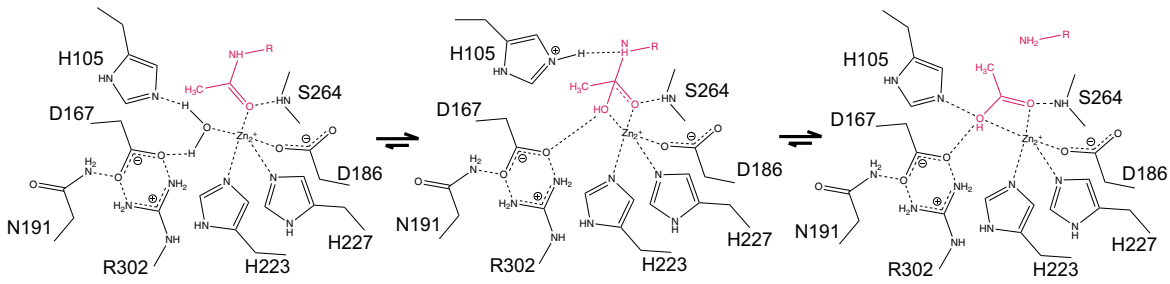

Fig. 5 PpID deacetylates GIcNAc in the GAC-peptidoglycan linkage region. a Predicted topology of PpID showing a transmembrane helix and structure of extracellular domain with the enzymatic active site is depicted on left panel. Right panel depicts the structure of ePpID viewing at the active site with the $\mathrm{Zn}^{2+}$ ion shown as a magenta sphere. $\mathbf{b}$ A close-up view of the active site PpID structure in complex with acetate. c The sacculi purified from GAS WT,

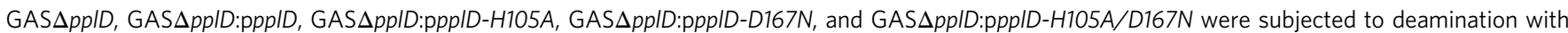
HONO. The concentration of GAC released from the sacculi was estimated by the modified anthrone assay and normalized to total GAC content in the analyzed materials. Symbols and error bars represent the mean and S.D., respectively ( $n=3$ biologically independent replicates). $P$ values were calculated by one-way ANOVA with Tukey's multiple comparisons test. Source data for (c) are provided as a Source data file. $\mathbf{d}$ Proposed catalytic mechanism for PpID-mediated deacetylation of the GAC-peptidoglycan linkage region.

lysozyme crossing the cell wall and binding to negatively charged bacterial membranes thus leading to membrane permeabilization. Deacetylation of GlcNAc in peptidoglycan by PgdA directly alters lysozyme binding to its substrate negatively affecting lysozymemediated degradation of peptidoglycan. Interestingly, in S. iniae, the PplD homolog also confers resistance to lysozyme ${ }^{43}$. Hence, to understand the role of cell wall deacetylation in protection of GAS against lysozyme, first, we assessed muramidase-dependent lysis of the WT GAS, GAS $\triangle p p l D$, GAS $\triangle p g d A$, and GAS $\triangle p p l D \triangle p g d A$ cells treated with lysozyme. When GAS strains were incubated with $1 \mathrm{mg} / \mathrm{ml}$ lysozyme for 18 hours, no lysozyme-dependent decrease in turbidity was observed consistent with the established high resistance of GAS to lysozyme. In contrast, incubation of GAS strains with an alternative highly efficient $\mathrm{N}$-acetylmuramidase, mutanolysin, produced a substantial drop in turbidity compared to control (Supplementary Fig. 7). Since the sensitivity of GAS to lysozyme appeared to be below the limits of detection detected by turbidity analysis, cell wall degradation was estimated with a more sensitive assay using dot-blot analysis for the water-soluble form of GAC released from the bacteria during digestion (Supplementary Fig. 8a). Lysozyme produced a very weak solubilization of GAC from WT GAS and
GAS $\triangle p p l D$ cells, and more pronounced release of GAC from GAS $\triangle p g d A$ and GAS $\triangle p p l D \Delta p g d A$ cells (Supplementary Fig. $8 \mathrm{~b}$ ). Furthermore, lysozyme released GAC from GAS $\triangle p p l D \Delta p g d A$ more efficiently, than from GAS $\triangle p g d A$ (Supplementary Fig. 8b). Altogether, these data indicate that lytic degradation of the GAS cell wall by lysozyme is minor due to the presence of GlcN in peptidoglycan as the result of PgdA catalytic activity. However, when PgdA is absent, deacetylation of the GAC linker region by $\mathrm{PplD}$ can be detected as a factor conferring protection against lysozyme-mediated lysis.

We previously reported that in comparison to the parental strain, the GroP-deficient mutant of GAS, GAS $\triangle g a c H$, is significantly more resistant to a highly cationic enzyme human group IIA secreted phospholipase $\mathrm{A}_{2}$ (hGIIA $s \mathrm{SLA}_{2}$ hereafter hGIIA $)^{15}$. This phenotype is likely due to either decreased binding of hGIIA to the cell surface or reduced permeability of the cell wall to hGIIA. Since deacetylation of GlcNAc residues increases the cell wall net positive charge, it might lead to neutralization of negative charges conferred by GroP moieties and as a result, affect the translocation of cationic AMPs across the cell wall. To understand how modulation of the cell wall net charge by deacetylation of GlcNAc residues alters susceptibility of 


\section{a}

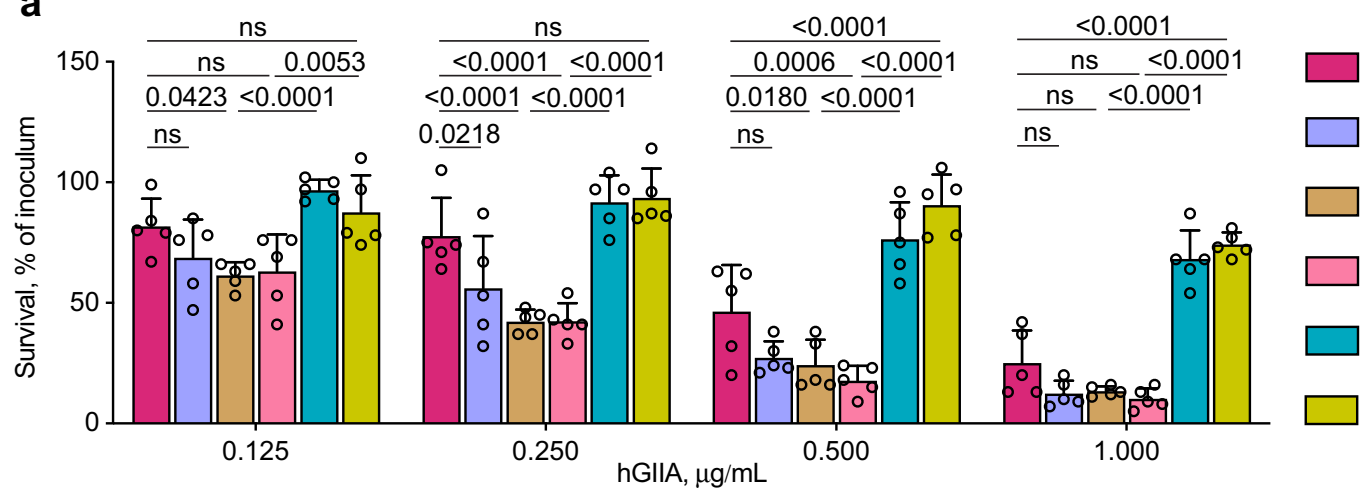

GAS WT

GAS $\triangle p g d A$

$\mathrm{AS} \triangle p p I D$

$\mathrm{GAS} \Delta p p / D \Delta p g d A$

GAS $\triangle p p / D: p p p / D$

GAS $\Delta p p I D \Delta p g d A: p p p I D$

b

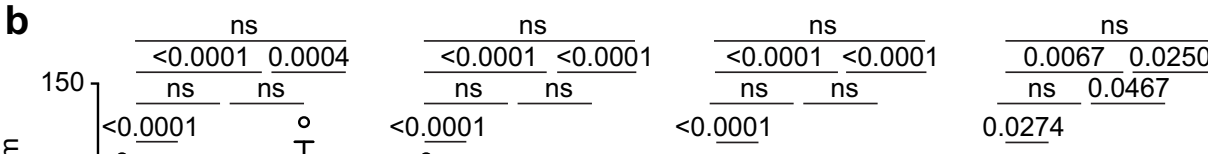
$\frac{\frac{n s}{0.0067} \underline{0.0250}}{\frac{\mathrm{ns}}{0.0467}}$

$\square$ GAS WT

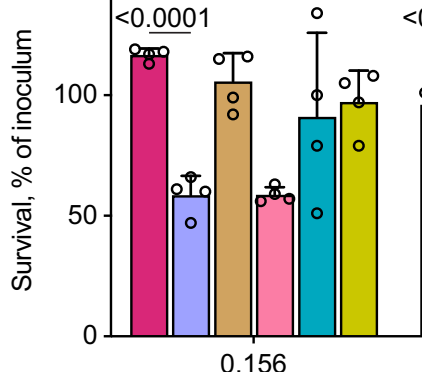

.0001 $<0.0001$

GAS $\triangle p g d A$
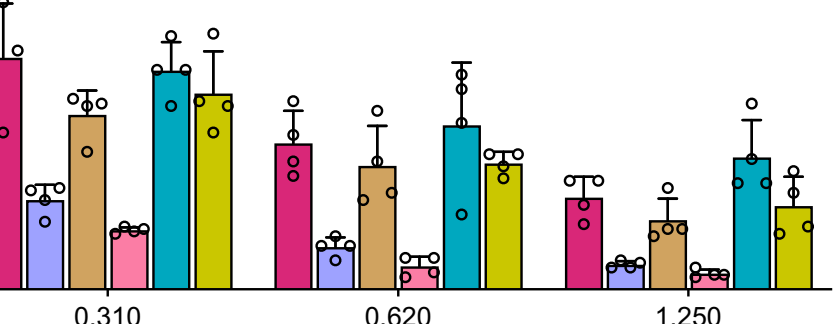

GAS $\triangle p p I D$

C lysozyme, $\mathrm{mg} / \mathrm{mL}$

0.620

1.250
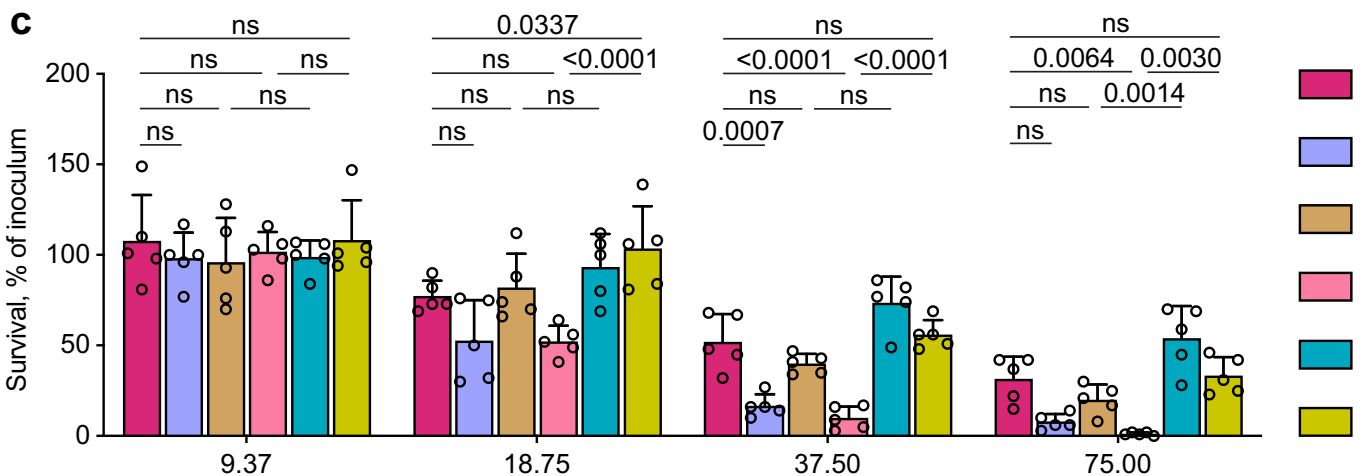

GAS WT

$\mathrm{GAS} \Delta p g d A$
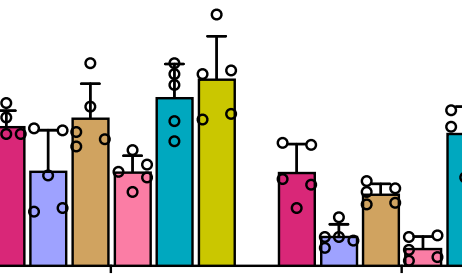

18.75

histones, $\mu \mathrm{g} / \mathrm{mL}$

37.50

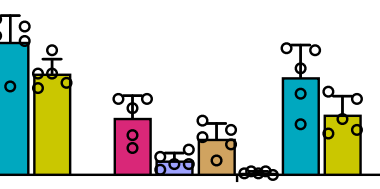

75.00

GAS $\triangle p p / D$

$\mathrm{GAS} \Delta p p / D \Delta p g d A$

GAS $\Delta p p / D: p p p / D$

GAS $\Delta p p / D \Delta p g d A: p p p / D$

Fig. 6 N-deacetylases PpID and PgdA contribute to protection of GAS against AMPs. a-c Analysis of resistance of GAC mutants deficient in Ndeacetylation of GlcNAc mediated by PpID and PgdA to $\mathbf{a}$ hGIIA, b lysozyme, and $\mathbf{c}$ histone mixture. Data are mean values \pm S.D., $n=5$ biologically independent experiments in $(\mathbf{a}, \mathbf{c}), n=4$ biologically independent experiments in (b). $P$ values were calculated by two-way ANOVA with Bonferroni's multiple comparison test. Source data are provided as a Source data file.

GAS to cationic AMPs, we analyzed the resistance of WT GAS, GAS $\triangle p p l D$, GAS $\triangle p g d A, G A S \Delta p p l D \Delta p g d A$ to the antimicrobial action of hGIIA, lysozyme, or histone mixture (Fig. $6 \mathrm{a}-\mathrm{c}$ and Supplementary Fig. 8c). We observed that deletion of either $p p l D$ or $p g d A$, or both genes, yielded strains with enhanced susceptibility to hGIIA (Fig. 6a). In contrast, deletion of $p p l D$ did not affect susceptibility of bacteria to lysozyme (Fig. 6b and Supplementary Fig. 8c) or a histone mixture (Fig. 6c). However, sensitivity to killing by these AMPs was significantly increased in $\mathrm{GAS} \triangle p g d A$ and GAS $\Delta p p l D \Delta p g d A$, with a more pronounced effect observed in GAS $\triangle p p l D \triangle p g d A$. Moreover, the expression of WT PplD in GAS $\triangle p p l D$ and GAS $\Delta p p l D \Delta p g d A$ significantly increased the resistance of the parental strains to the AMPs, especially for hGIIA (Fig. 6a-c and Supplementary Fig. 8c). This observation correlates with the conclusion that the level of deacetylation of the GAC-peptidoglycan linkage region in the complemented strains is higher than in the WT strain, and indicates that both PgdA and PplD enhance resistance of GAS to the tested AMPs.

Finally, we examined susceptibility of the GroP-deficient mutant, GAS $\triangle g a c H$, and its complemented strain, GAS $\Delta g a c H$ :p$g a c H$, to the antimicrobial action of lysozyme or histones to confirm that the mechanisms of lysozyme and histone killing of GAS are charge-dependent. Deletion of gacH rendered GAS more resistant to lysozyme and histones, and the phenotype was reversed by complementation of GAS $\triangle g a c H$ with WT $g a c H$ (Fig. 7a, b). Collectively, our results are consistent with a model in which the addition of positive residues by deacetylation of GlcNAc in peptidoglycan and the GAC linkage region counteracts the cell wall net negative charge provided by GroP moieties resulting in reduced translocation of cationic AMPs across the cell wall (Fig. 7c). 
a $\square$ GAS WT $\square$ GAS $\triangle$ gach $\square$ GAS $\triangle$ gach:pgacH

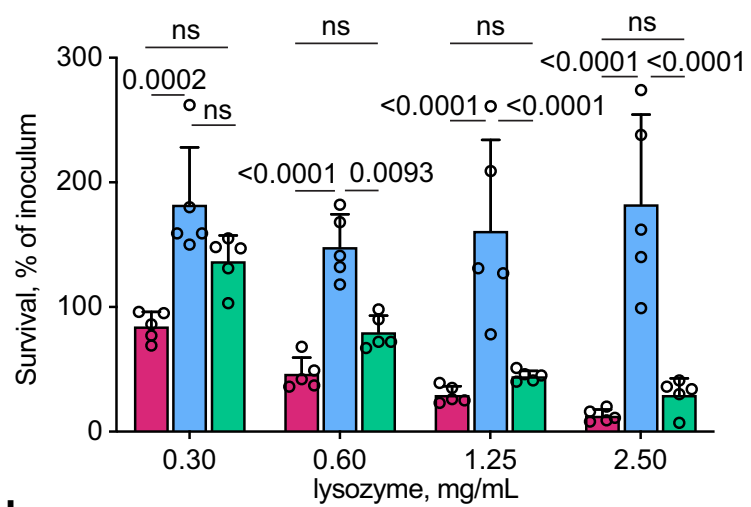

b

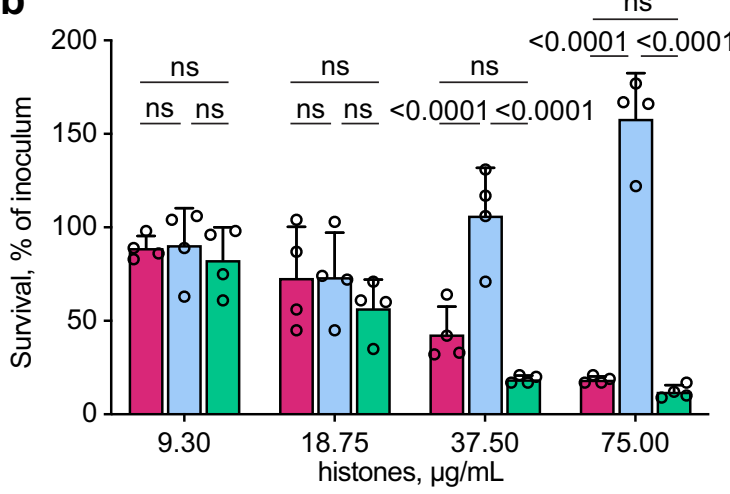

C

Negative charges on phosphates decrease resistance to antimicrobial proteins

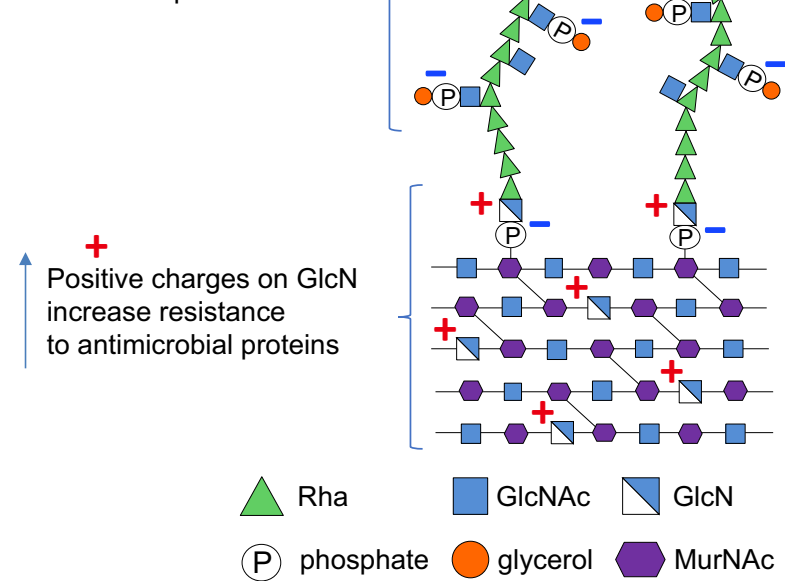

Fig. 7 The role of the GroP modification in GAS protection against histones and lysozyme. $\mathbf{a}$, $\mathbf{b}$ Analysis of resistance of GAC mutants deficient in the GroP modification to $\mathbf{a}$ lysozyme, and $\mathbf{b}$ histone mixture. Data are mean values \pm S.D., $n=5$ biologically independent experiments in (a), $n=4$ biologically independent experiments in (b). $P$ values were calculated by two-way ANOVA with Bonferroni's multiple comparison test. Source data for $(\mathbf{a}, \mathbf{b})$ are provided as a Source data file. $\mathbf{c}$ Introduction of charges to the GAS cell wall by GIcNAc deacetylation and GroP modification modulates resistance to host cationic antimicrobial proteins.
PplD homologs deacetylate respective rhamnopolysaccharides in streptococci. To understand whether deacetylation of the polysaccharide-peptidoglycan linkage region is widespread in bacteria, we examined the distribution of the PplD family of proteins throughout the bacterial kingdom. PplD homologs were predominantly identified in the genomes of streptococcal species (Supplementary Fig. 9). Interestingly, members of the S. mitis group, that express choline-containing WTAs, and not Rhacontaining polysaccharides, possess only the PgdA homolog, supporting the conclusion that PplD is only active on rhamnopolysaccharides. We also observed that genes encoding $p p l D$ homologs in a number of streptococcal strains contain a frame shift mutation and thus are likely non-functional. Hence, to investigate the function of PplD in streptococcal species, we selected for analysis the following strains: Streptococcus agalactiae (Group B Streptococcus, GBS) A909, S. mutans Xc, and Streptococcus equi subsp. equi CF32 in which pplD is an intact gene, and GBS COH1 and Streptococcus thermophilus LMG 18311 in which the pplD homologs have a frame shift mutation (Supplementary Fig. 10). Additionally, we deleted the $p p l D$ homologs in S. mutans Xc and GBS A909 strains creating the SMU $\Delta p p l D$ and GBS $\triangle p p l D$ strains. In agreement with the function of PplD in deacetylation of the polysaccharide-peptidoglycan linker, the rhamnopolysaccharides were liberated from the cell walls by HONO in the strains with the intact pplD (Fig. 8a, b). In contrast, this treatment did not cleave the polysaccharides from the strains carrying the inactivated $p p l D$. However, these polysaccharides were released by mild acid hydrolysis (Fig. 8a, b). Furthermore, expression of the GAS WT PplD but not the catalytically inactive versions of $\mathrm{PplD}$, PplD-D167N, and PplD-H105A/D167N, restored the phenotype of SMU $\triangle p p l D$ (Fig. 8a). Taken together, the results support the conclusion that in the large group of streptococci expressing the Rha-containing polysaccharides, the polysaccharide-peptidoglycan linkage region is deacetylated by PplD homologs suggesting that PplD recognizes for catalysis the polyrhamnose linker region sugars that are conserved in many streptococci ${ }^{1,16}$.

\section{Discussion}

Currently, no licensed vaccine exists for GAS which is a leading cause of morbidity and mortality worldwide. Glycoconjugate vaccines obtained by covalent linkage of bacterial polysaccharides to carrier proteins have been proven highly successful in the prevention of a number of infectious diseases ${ }^{54}$. The major component of GAS cell wall, GAC, is an important determinant of viability and virulence, and is a promising target for the development of vaccines to treat GAS infections. One of the obstacles to the GAC-based vaccine development is the lack of efficient and structurally accurate methods of GAC conjugation to protein carriers ${ }^{9}$, primarily as a result of misperceptions of the chemical nature of the GAC-peptidoglycan linkage unit. A consequence of this incomprehension is that previous methods for preparation of GAC have either been notably inefficient or relied on harsh chemical treatments for polysaccharide cleavage and the insertion of reactive chemical groups required for coupling reactions to carrier proteins $s^{6-11}$. In this report, using NMR studies together with chemical degradation and glycosyl composition analysis, we demonstrate that a significant fraction of GAC contains GlcN 1-phosphate in the peptidoglycan linkage unit. This previously unrecognized structural feature of the GAC introduces a positive charge at the site of attachment to peptidoglycan, rendering the GAC-peptidoglycan linkage resistant to cleavage by mild acid, but sensitive to cleavage by HONO. Importantly, our study reveals that mild acid hydrolysis, following chemical $\mathrm{N}$-acetylation produces nearly quantitative release of 


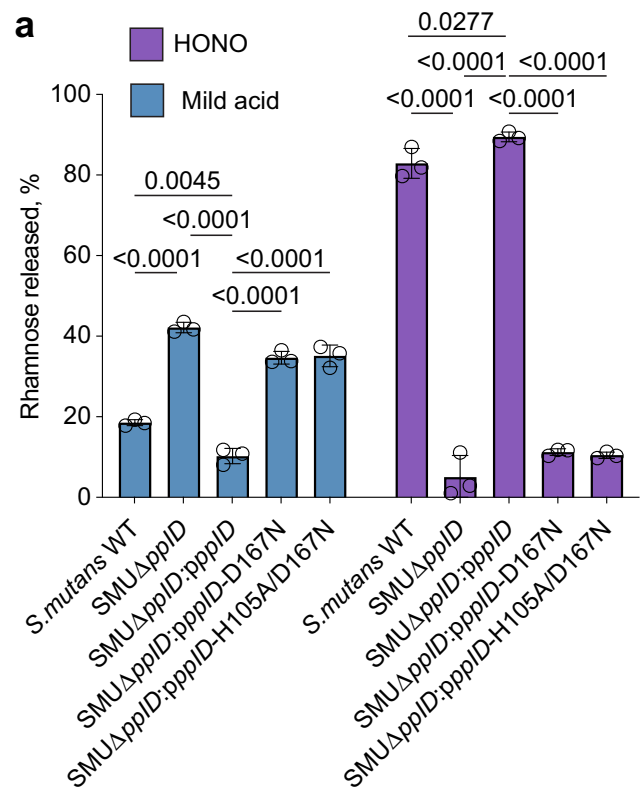

b

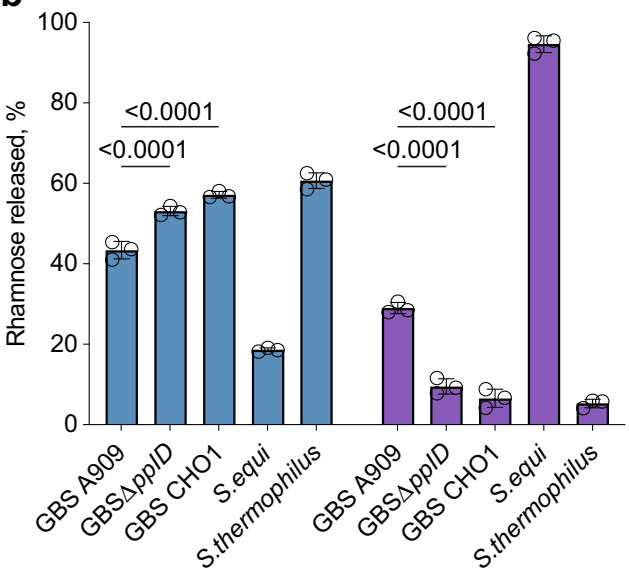

Fig. 8 Analysis of PpID-mediated deacetylation in streptococcal species. a Release of SCC from the sacculi purified from S. mutans strains by mild acid hydrolysis (left) or deamination with HONO (right). b Release of the Rha-containing polysaccharides from the cell wall purified from GBS, S. equi and $S$. thermophilus strains by mild acid hydrolysis (left) or deamination with HONO (right). The concentration of polysaccharide released from the sacculi or cell wall was estimated by the modified anthrone assay and normalized to total content of polysaccharide in the starting material. Symbols and error bars represent the mean and S.D., respectively $(n=3$ biologically independent replicates). $P$ values were calculated by two-way ANOVA with Tukey's multiple comparisons test. Source data are provided as a Source data file.

GAC with a reducing end sugar (GlcNAc) which is suitable for efficient coupling to free amino groups of target proteins by reductive amination. GAC released by this gentle method provides a much more appropriate substrate for preparation of immunogens because all labile substituents are preserved. Thus, this improved insight into the chemical structure of the GACpeptidoglycan linkage and the products generated by chemical treatments will guide optimization of conjugation processes with GAC resulting in production of well-defined homogeneous glycoconjugate vaccine.

Previously, similar sensitivity to cleavage by mild acid and HONO was only observed for the WTA of L. plantarum AHU $1413^{20}$. We extended the analysis of sensitivity of polysaccharide cleavage by these treatments to other streptococcal species revealing the presence of GlcN residues in the Rha-containing polysaccharide linkers of GBS, $S$. mutans and $S$. equi. In bacteria, enzymatic deacetylation of GlcNAc residues in peptidoglycan, chitin and the exopolysaccharide PNAG is carried out by CE4 family enzymes $42,47,55,56$. GAS, S. mutans, S. equi, and GBS genomes encode two CE4 enzymes, the peptidoglycan deacetylase PgdA and the PplD protein. Using sensitivity to polysaccharide cleavage by mild acid and HONO, we demonstrate that PplD is critical for deacetylation of GlcNAc in the linkage unit of the Rhacontaining polysaccharides of GAS, GBS and S. mutans. The structural analysis of GAS PplD together with the functional analysis of the site-directed mutants, H105A and D167N, further supports this conclusion. We show that PplD is a metalloenzyme with an active site $\mathrm{D}-\mathrm{H}-\mathrm{H}$ triad coordinating a $\mathrm{Zn}^{2+}$ ion. The enzymatic mechanism involves a $\mathrm{Zn}^{2+}$-coordinated water molecule acting as a nucleophile, and a conserved histidine residue, $\mathrm{H} 105$, acting as a bifunctional acid/base catalyst.

Phylogenetic analysis of PplD homologs in bacterial genomes suggests the occurrence of GlcN 1-phosphate in the peptidoglycan linkage of the polysaccharides in the majority of streptococci except for a few members of the $S$. mitis group that decorate peptidoglycan with choline-containing WTAs. Thus, the presence of PplD in bacterial genomes correlates with the expression of the Rha-containing polysaccharides in these bacteria. Interestingly, the GlcN content of the GAC linkage region varies considerably in the analyzed streptococcal species, from very high in the $S$. equi, S. mutans and GAS strains (about 80-90\%) to rather intermediate in GBS A909 (about 30\%). Our analysis of the two GAC isoforms with GlcN and GlcNAc linker residues indicates that they are chromatographically and compositionally identical, except for $N$-acetylation of the linkage unit GlcN. Since GAC is presumably synthesized with GlcNAc 1-phosphate at the reducing terminus and it seems unlikely that the LCP transferases catalyzing the transfer of the glycan to cell wall would accept both $\mathrm{N}$-acetyl-containing substrates and those devoid of this group, $N$-deacetylation probably occurs after transfer to cell wall. This conclusion is supported by the observation that GlcNAc 1-phosphate-linked polysaccharides, released from GAS saccules by mild acid, appear to be primarily localized to regions of active cell wall synthesis. The simplest explanation is that the nascent GAC chains have not yet had an opportunity to interact with PplD.

At this time, it is not clear what primary advantage deacetylation of linkage unit GlcNAc units might confer on individual streptococci. Introduction of the positive charge into the linkage unit could conceivably stabilize the phosphodiester linkage. However, the presence of the primary amine might also present a vulnerability to hydrolysis by acidified nitrite. In mammals, sodium nitrite serves as a source for generation of nitric oxide (NO), a central biological mediator ${ }^{23}$. Nitrite is formed via the enzymatic oxidation of $\mathrm{NO}$ in the blood and tissues ${ }^{57}$, and reduction of dietary nitrate by anaerobic bacteria colonizing the oral cavity and gastrointestinal tract ${ }^{58}$. In the oral cavity, nitrite is actively concentrated by salivary glands reaching up to $2 \mathrm{mM}$ after a dietary nitrate load ${ }^{58}$. The Streptococcus genus dominates the majority of oral surfaces ${ }^{59}$. These bacteria produce byproducts of fermentation, lactic and acetic acids, that cause a significant decrease in $\mathrm{pH}$ level to 5.5 and below, which is sufficient to release the rhamnopolysaccharides from streptococcal species by deamination using nitrite. Since oral microbiota affect many aspects of human health, one may wonder whether streptococci shed the polysaccharides in vivo, and whether the products of hydrolysis, free polysaccharide and unmasked peptidoglycan, induce host immune responses and contribute to the complex interplay of oral microbiota. 
In S. iniae, the PplD homolog was previously identified as a significant virulence factor promoting bacterial infection. The $S$. iniae pplD mutant displayed attenuated virulence in the hybrid striped bass model, decreased survival in whole fish blood and increased sensitivity to lysozyme killing ${ }^{43}$. We demonstrate that in GAS, PplD and PgdA $N$-deacetylases promote resistance to cationic AMPs (lysozyme, hGIIA, and histones). These AMPs vary from 14 to $21 \mathrm{kDa}$ in size, and attack pathogens by divergent mechanisms ${ }^{60}$. hGIIA catalyzes the hydrolysis of bacterial phospholipids including phosphatidylglycerol ${ }^{61-63}$ and is considered a major human host-protective factor against Gram-positive pathogens ${ }^{64-66}$. Lysozyme catalyzes the hydrolysis of glycosidic bonds of peptidoglycan. The antimicrobial action of histones has been attributed to the disruption of membrane integrity ${ }^{67}$. Furthermore, similar to histones, lysozyme and hGIIA can insert into negatively charged bacterial membrane forming pores ${ }^{52,68-71}$. The decreased resistance of the mutants defective in PplD and PgdA to the tested AMPs may be explained by a decrease of the positive charge inside the cell wall. To reach the plasma membrane, AMPs have to traverse the Gram-positive cell envelope. There is substantial evidence that changes in the net charge of cell envelope components, peptidoglycan and teichoic acids, modulate the resistance of bacteria to AMPs ${ }^{63,66,72-75}$. We previously demonstrated that modification of GAC and the $S$. mutans rhamnopolysaccharide with negatively charged GroP moieties renders GAS and $S$. mutans more sensitive to hGIIA activity ${ }^{15}$. In this study, we reveal that the GroP modification confers sensitivity of GAS to lysozyme and histone mixture also. Thus, these data support the conclusion that PplD and PgdA contribute to protection of bacteria against AMPs by neutralizing a net negative charge of the cell wall polysaccharides (Fig. 7c).

In sum, the results of this study form a foundation for the design of significantly improved GAS glycoconjugate vaccine based on GAC and provide insight into the function of cell wall modifications in protection of bacteria against cationic AMPs.

\section{Methods}

Bacterial strains, growth conditions, and media. All plasmids, strains and primers used in this study are listed in Supplementary Tables 5 and 6. Streptococcal strains were grown in BD Bacto Todd-Hewitt broth supplemented with $1 \%$ yeast extract (THY) without aeration at $37^{\circ} \mathrm{C}$. S. mutans strains were grown on THY agar at $37^{\circ} \mathrm{C}$ with $5 \% \mathrm{CO}_{2}$. E. coli strains were grown in Lysogeny Broth (LB) medium or on $\mathrm{LB}$ agar plates at $37^{\circ} \mathrm{C}$. When required, antibiotics were included at the following concentrations: ampicillin and streptomycin at $100 \mu \mathrm{g} \mathrm{mL}^{-1}$ for $E$. coli; erythromycin at $500 \mu \mathrm{g} \mathrm{mL} \mathrm{m}^{-1}$ for $E$. coli and $5 \mu \mathrm{g} \mathrm{mL}{ }^{-1}$ for streptococci; chloramphenicol at $10 \mu \mathrm{g} \mathrm{mL}^{-1}$ for $E$. coli and $2 \mu \mathrm{g} \mathrm{mL}^{-1}$ for streptococci; spectinomycin at $200 \mu \mathrm{g} \mathrm{mL}^{-1}$ for E. coli and $200 \mu \mathrm{g} \mathrm{mL}^{-1}$ for streptococci; kanamycin at $50 \mu \mathrm{g} \mathrm{mL}^{-1}$ for E. coli and $300 \mu \mathrm{g} \mathrm{mL}^{-1}$ for streptococci.

Construction of mutant strains. For construction of the GAS, GBS and S. mutans deletion mutants, GAS NZ131, GBS A909, and S. mutans Xc chromosomal DNA, respectively, were used as the templates for amplification of DNA fragments encompassing the upstream and downstream regions flanking the gene of interest. The primers used to generate the deletion mutants are listed in Supplementary Table 6. To construct GAS $\triangle p p l D$, the DNA fragments were amplified using two primers pairs JC480/JC481 and JC482/JC483, digested with the restriction enzymes and cloned into pFED760 76 . The antibiotic resistance cassette for kanamycin (aph3A), amplified from pOskar ${ }^{77}$ using two primers pairs JC292/JC304, was cloned between the upstream and downstream fragments to generate the plasmid pJC344-kan for selective allelic replacement. The plasmid was electroporated into the GAS NZ131 cells.

To construct GAS $\Delta p p l D \Delta p g d A$, two DNA fragments were amplified using two primers pairs PplD-BglII-F/PplD-SalI-R and PplD-BamH-F/PplD-XhoI-R (Supplementary Table 2), digested with BglII/SalI and ligated into BglII/SalIdigested pUC19BXspec ${ }^{13}$. The resultant plasmid was digested with BamHI/XhoI, and used for ligation with the second PCR product that was digested with BamHI/ XhoI. The resultant plasmid, pUC19BXspec-pplD, was digested with BglII and XhoI to obtain a DNA fragment containing a nonpolar spectinomycin resistance cassette flanked with the pplD upstream and downstream regions. This DNA fragment was cloned into BglII/XhoI-digested pHY304 to generate pHY304 $\Delta p p l D$ NZ131. The resultant plasmid was electroporated into the GAS $\Delta p g d A^{78}$
To construct GAS $\Delta g a c H$, GBS $\Delta p p l D$, and SMU $\Delta p p l D$, we used a PCR overlapping mutagenesis approach, as previously described ${ }^{15}$. Briefly, $600-700 \mathrm{bp}$ fragments both upstream and downstream of the gene of interest were amplified with designed primers that contained $16-20$ bp extensions complementary to the nonpolar antibiotic resistance cassette (Supplementary Table 6). The nonpolar spectinomycin and chloramphenicol resistance cassettes were PCR-amplified from pLR16T and pDC123, (Supplementary Table 5), respectively, and used for mutagenesis of $p p l D$ and $g a c H$, respectively. Two fragments flanking the gene of interest and the antibiotic resistance cassette were purified using the QIAquick PCR purification kit (Qiagen) and fused by Gibson Assembly (SGA-DNA). A PCR was then performed on the Gibson Assembly sample using primers listed in (Supplementary Table 6) to amplify the fused fragments. The assembled DNA fragment for mutagenesis of $S$. mutans pplD was directly transformed into the $S$. mutans Xc cells by electroporation. The transformants were selected on THY agar containing spectinomycin.

The assembled DNA fragments for mutagenesis of GAS gacH and GBS $p p l D$ were cloned into pHY304 by the use of restriction enzymes to generate the plasmids pHY304 $\mathrm{gacH}-\mathrm{NZ131}$ and $\mathrm{pHY} 304 \Delta p p l D$-GBS, respectively. The plasmids were electroporated into the GAS NZ131 and GBS A909 cells to obtain $\mathrm{GAS} \Delta g a c H$ and GBS $\Delta p p l D$, respectively.

A two-step temperature-dependent selection process was used to isolate the desired GAS and GBS mutants ${ }^{15}$. The transformants were selected on THY agar containing the corresponding antibiotic and screened for sensitivity to erythromycin. Single colonies sensitive to erythromycin were picked. Doublecrossover recombination was confirmed by PCR and Sanger sequencing using the primers listed in Supplementary Table 6.

For complementation of GAS $\Delta p p l D$, GAS $\Delta p p l D \Delta p g d A$, and SMU $\Delta p p l D$, a promoterless $p p l D$ gene was amplified from GAS NZ131 using the primers listed in Supplementary Table 6 . The PCR product was ligated into $\mathrm{pDC1} 23$ vector, yielding $\mathrm{p} p p l D$. To make a catalytically inactive variant of $p p l D$, the mutations $\mathrm{H} 105 \mathrm{~A}$ and D167N were introduced into ppplD using Gibson Assembly site-directed mutagenesis (SGI-DNA) with the primers listed in Supplementary Table 6, yielding the ppplD-H105A, ppplD-D167N, and ppplD-H105A/D167N plasmids. The plasmids were transformed into GAS $\Delta p p l D$, GAS $\Delta p p l D \Delta p g d A$, and SMU $\Delta p p l D$. Chloramphenicol resistant single colonies were picked and checked for presence of ppplD by PCR and Sanger sequencing. Complementation of GAS $\Delta g a c H$ with WT gacH and $\mathrm{gacH}-\mathrm{T530A}$ on pDCerm expression plasmid was conducted as previously described ${ }^{15}$.

Construction of the plasmids for expression of ePpID and GFP-AtIA ${ }^{\text {Efs }}$. To create a vector for expression of the extracellular domain of PplD (ePplD), the gene was amplified from GAS 5005 chromosomal DNA using the primer pair pplDNcoI-f and pplD-XhoI-r. The PCR product was digested with NcoI and XhoI, and ligated into NcoI/XhoI-digested pCDF-NT vector. The resultant plasmid, pCDFPplD, encodes pplD fused at the N-terminus with a His-tag followed by a TEV protease recognition site. To construct a vector for expression of GFP-AtlA ${ }^{\mathrm{Efs}}$ (pKV1644), $5^{\prime}$ fragment encoding GFP was PCR-amplified from pHR-scFv-GCN4 sfGFP-GB1-NLS-dWPRE using primer pairs sfGFP_BspH and gfp-0799-R, and $3^{\prime}$ fragment encoding a C-terminal cell wall-binding domain of AtlA was amplified from E. faecalis V583 DNA using the primer pair gfp-0799-F and 0799-Hind. GFP fusion was constructed using a PCR overlapping mutagenesis approach, digested with BspHI/HindIII and ligated into NcoI/HindIII-digested pRSF-NT vector.

Crystallization and structure determination of ePpID. E. coli Rosetta (DE3) cells carrying pCDF-PplD were grown to an $\mathrm{OD}_{600}$ of 0.6 and induced with $0.25 \mathrm{mM}$ isopropyl $\beta$-D-1-thiogalactopyranoside (IPTG) at $18^{\circ} \mathrm{C}$ for approximately $16 \mathrm{~h}$. The cells were lysed in $20 \mathrm{mM}$ Tris- $\mathrm{HCl} \mathrm{pH} 7.5,300 \mathrm{mM} \mathrm{NaCl}$ using a microfluidizer cell disrupter. The soluble fractions were purified by Ni-NTA chromatography as previously reported for $\mathrm{GacH}^{15}$. The eluate was dialyzed into $20 \mathrm{mM}$ Tris- $\mathrm{HCl} \mathrm{pH} \mathrm{7.5,} 300 \mathrm{mM} \mathrm{NaCl}$ in the presence of TEV protease $(1 \mathrm{mg}$ per $20 \mathrm{mg}$ of protein). The dialyzed sample was reapplied to a Ni-NTA column equilibrated in $20 \mathrm{mM}$ Tris- $\mathrm{HCl} \mathrm{pH} 7.5,300 \mathrm{mM} \mathrm{NaCl}$. ePplD was further purified by size exclusion chromatography on a Superdex 200 column in $20 \mathrm{mM}$ HEPES pH 7.5, $100 \mathrm{mM} \mathrm{NaCl}$. Fractions collected during elution from the column were analyzed for purity by SDS-PAGE (Supplementary Fig. 11) and concentrated to $4.7 \mathrm{mg} / \mathrm{mL}$. Initial screening for crystallization conditions was performed using MCSG I-IV crystallization screens (Anatrace). The optimized crystals were obtained using the vapor diffusion method in 20\% PEG3350, 0.2 M zinc acetate, $0.1 \mathrm{M}$ imidazole, $\mathrm{pH}$ 8.0. Crystals were transferred to crystallization solution supplemented with $20 \%$ glycerol and vitrified in liquid nitrogen prior to data collection. Due to the presence of $\mathrm{Zn}^{2+}$ ions in the crystallization solution, the data were collected above $\mathrm{Zn}$ anomalous scattering edge at wavelength $1.27 \AA$ at beamline BL9-2 at the Stanford Synchrotron Radiation Laboratory (SSRL) using Blu-Ice 5. The data were processed and scaled using XDS and XSCALE ${ }^{79}$. The structure was solved by singlewavelength anomalous diffraction phasing using an automated Phaser SAD pipeline ${ }^{80}$. The initial zinc positions were found using SHELXD ${ }^{81}$. Following density modification with Parrot, the initial model was built using Buccaneer ${ }^{82,83}$. The model was improved using manual rebuilding in Coot alternating with refinement by phenix.refine $e^{84,85}$. The final model had $96 \%$ of residues in the favorable region of the Ramachandran plot and $4 \%$ in additionally allowed region. 
Lysozyme, hGIIA, and histone susceptibility assay. Frozen stocks of GAS variants were used for microbial susceptibility tests with hGIIA, histone mixture from calf thymus (Millipore Sigma, 10223565001) and lysozyme from egg white (Millipore Sigma, L6876). Recombinant hGIIA was produced as described previously ${ }^{86}$. To make frozen aliquots, GAS strains, cultured overnight in THY medium, were diluted 1:100 into fresh THY medium and allowed to grow to mid-logarithmic phase $\left(\mathrm{OD}_{600}=0.5\right)$. Bacteria were collected by centrifugation, washed twice with PBS and re-suspended in HEPES buffer solution (20 mM HEPES pH 7.5, $2 \mathrm{mM}$ $\mathrm{CaCl}_{2}$ and $1 \% \mathrm{BSA}$ ) with $15 \%$ glycerol. The aliquots were frozen and stored at $-80^{\circ} \mathrm{C}$ until used in viability assays. Aliquots were thawed and diluted to $1: 1000$ in HEPES buffer solution. The susceptibility experiments were performed as described previously ${ }^{75}$. Briefly, the AMP (hGIIA, lysozyme, and histone mixture) was serially diluted in HEPES solution. Diluted bacterial cultures $(10 \mu \mathrm{l})$ were mixed with the AMP $(10 \mu \mathrm{l})$ in a conical 96-well plate. The plate was incubated at $37^{\circ} \mathrm{C}$ with $5 \% \mathrm{CO}_{2}$ for $2 \mathrm{~h}$. After incubation, the bacterial suspensions were diluted with $200 \mu \mathrm{l}$ PBS and $40 \mu \mathrm{l}$ was plated on THY agar plates $(10 \mathrm{~cm})$ for quantification. After overnight incubation, the CFU were counted. Survival rate was calculated as Survival $(\%$ of inoculum $)=($ counted CFU * 100)/CFU count of original (no AMP added sample). Drop test assay with varying concentrations of lysozyme was conducted as previously described for zinc concentrations ${ }^{15}$.

Muramidase activity of lysozyme on GAS. Overnight cultures of the GAS strains were diluted (1:100) into fresh THY broth and grown to an $\mathrm{OD}_{600}$ of 0.5. Cell suspension $(10 \mathrm{~mL})$ was centrifuged $(3200 \times g, 10 \mathrm{~min})$ and resuspended with either $1 \mathrm{mg} \mathrm{mL}^{-1}$ lysozyme or $62.5 \mathrm{U} / \mathrm{ml}$ mutanolysin (Sigma, M9901) or no enzyme (negative control) in sterile PBS $(10 \mathrm{~mL})$. After 0 and $18 \mathrm{~h}$ of incubation at $37^{\circ} \mathrm{C}, 0.2 \mathrm{~mL}$ was centrifuged $(16,000 \times g, 3 \mathrm{~min})$. The supernatant was transferred to a fresh centrifuge tube and concentrated to $30 \mu \mathrm{l}$ final volume using SpeedVac vacuum concentrator. Supernatant $(5 \mu \mathrm{l})$ was spotted on a nitrocellulose membrane. The membrane was blocked for $1 \mathrm{~h}$ with $7 \%$ skim milk in PBS $/ 0.1 \%$ Tween 20 and incubated with an anti-GAC antibody diluted 1:5000 (Abcam, ab9191). Bound antibodies were detected with a peroxidase-conjugated goat anti-rabbit IgG antibody and the Amersham Bioscience ECL (enhanced chemiluminescence) western blotting system. ImageJ software was used to quantify the signal of polysaccharides released.

Isolation of cell wall and sacculi. Cell wall was isolated from exponential phase cultures by the SDS-boiling procedure as described for S. pneumoniae ${ }^{87}$. Purified cell wall samples were lyophilized and stored at $-20^{\circ} \mathrm{C}$ before the analysis. $S$. mutans and GAS sacculi were obtained by the SDS-boiling procedure followed by 2 washes with $1 \mathrm{M} \mathrm{NaCl}$ and 5 washes with water as outlined ${ }^{25}$. To analyze sensitivity of GAC cleavage to chemical treatments, the GAS sacculi were additionally treated with $5 \mathrm{mg} \mathrm{mL}^{-1}$ trypsin (Sigma, T-8253) at $37^{\circ} \mathrm{C}$ overnight, sedimented $(32,000 \times g$ for $15 \mathrm{~min})$, and washed 4 times by resuspension in water. This treatment removes binding of the GAS sacculi to the microcentrifuge plastic tubes. Sacculi were resuspended in water and stored at $4{ }^{\circ} \mathrm{C}$ before the analysis.

HONO deamination. Polysaccharide was released from sacculi or highly enriched cell wall preparations by HONO deamination essentially as described ${ }^{22}$ with minor modification. Briefly, reactions contained sacculi $\left(\mathrm{OD}_{600}=3.4\right)$ or isolated cell walls $\left(2-5 \mathrm{mg} \mathrm{mL}^{-1}\right)$, in $0.2 \mathrm{~N} \mathrm{Na}$ Acetate $\mathrm{pH} 4.5$ and $1.5 \mathrm{M} \mathrm{NaNO}_{2}$ (added in three equal portions over a period of $90 \mathrm{~min}$ ) at room temperature. Following deamination, the reaction was stopped by the addition of one equivalent of ethanolamine and centrifuged $(60,000 \times g, 10 \mathrm{~min})$. The supernatant was removed and transferred to an Amicon Ultra- $0.5 \mathrm{~mL}$ (3000 MWCO) spin filter. The pellet was washed two times by resuspension in water ( $1 / 2$ of the original reaction volume), re-sedimented, and the washings were combined with the initial supernatant. The washed pellet was re-suspended in water and reserved for analysis, or discarded. The released material was desalted by several sequential cycles of dilution with water and re-concentration on the spin filter, recovered in a convenient volume of water and either reserved for analysis or purified further by chromatography on Bio Gel P150 and ion exchange on DEAE-Toyopearl.

Mild acid hydrolysis. Mild acid hydrolysis was performed, either with or without prior $N$-acetylation, as previously described for WTA of $L$. plantarum ${ }^{20}$ with some modifications. Chemical $\mathrm{N}$-acetylation reactions contained sacculi $\left(\mathrm{OD}_{600}=3.4\right)$ or isolated cell walls $(2-5 \mathrm{mg} / \mathrm{ml})$, resuspended in $1 \mathrm{~mL}$ of saturated $\mathrm{NaHCO}_{3}$, and $2 \%$ acetic anhydride. After $1 \mathrm{~h}$ on ice, the reactions were allowed to warm to room temperature overnight. After incubation at room temperature overnight, the reactions were diluted with 2 volumes of water and sedimented $(50,000 \times g$, $10 \mathrm{~min}$ ). The insoluble residue was washed three times by resuspension with $3 \mathrm{~mL}$ water followed by sedimentation $(50,000 \times g, 10 \mathrm{~min})$. For mild acid hydrolysis, sacculi or cell wall material was re-suspended in $0.02 \mathrm{~N} \mathrm{HCl}$ and heated to $100^{\circ} \mathrm{C}$ for $20 \mathrm{~min}$. The reactions were cooled on ice, neutralized by the addition of $1 \mathrm{~N}$ $\mathrm{NaOH}(1$ equivalent) and sedimented $(50,000 \times g, 10 \mathrm{~min})$. The supernatant fraction was removed and reserved, and the pellet was re-suspended in water and resedimented. The supernatant fractions were combined and either analyzed or purified further. The pellet fractions were resuspended in an equal volume of water and reserved for further analysis for rhamnose content or used for fluorescent microscopy.

\section{Fluorescent and differential interference contrast (DIC) microscopy. GAS} sacculi obtained by the SDS-boiling procedure were subjected to mild acid hydrolysis or deamination with HONO as outlined above. Untreated or treated sacculi were resuspended in PBS to an $\mathrm{OD}_{600}=0.3$, and incubated with $19.8 \mu \mathrm{g} \mathrm{mL}$ ${ }^{-1}$ GFP-Atli ${ }^{\mathrm{Efs}}$ for $30 \mathrm{~min}$ at room temperature. The samples were washed three times with water, dried at room temperature, and mounted on a microscope slide with ProLong Glass Antifade (Invitrogen). Samples were imaged on a Leica SP8 equipped with 100X, 1.44 N.A. objective and DIC optics.

Chromatography of GAC. GAC, released by either deamination with HONO or by mild acid treatment, was partially purified by size-exclusion chromatography (SEC) on a $1 \times 18 \mathrm{~cm}$ column Bio Rad BioGel P150 equilibrated in $0.2 \mathrm{~N} \mathrm{Na}$ acetate, $\mathrm{pH}$ 3.7, $0.15 \mathrm{M} \mathrm{NaCl}$. Following SEC, GAC was further fractionated by ion-exchange chromatography on a $1 \times 18 \mathrm{~cm}$ column of DEAE-Toyopearl (TosoHaas) equilibrated in $10 \mathrm{mM}$ HEPES, $\mathrm{pH} 8$. After elution with two column volumes, DEAEbound glycans were eluted with an $80 \mathrm{~mL}$ gradient $(0-0.5 \mathrm{M})$ of $\mathrm{NaCl}$.

Phosphate assays. During GAC purification, total phosphate content was determined by the malachite green method following digestion with perchloric acid. Fractions containing $10-80 \mu \mathrm{L}$ were heated to $110^{\circ} \mathrm{C}$ with $40 \mu \mathrm{L} 70 \%$ perchloric acid (Fisher Scientific) in $13 \times 100$ borosilicate disposable culture tubes for $1 \mathrm{~h}$. The reactions were diluted to $160 \mu \mathrm{L}$ with water and $100 \mu \mathrm{L}$ was transferred to a flat-bottom 96-well culture plate. Malachite Green reagent $(0.2 \mathrm{~mL})$ was added and the absorbance at $620 \mathrm{~nm}$ was read after $10 \mathrm{~min}$ at room temperature. Malachite Green reagent contained 1 vol $4.2 \%$ ammonium molybdate tetrahydrate (by weight) in $4 \mathrm{M} \mathrm{HCl}, 3$ vol $0.045 \%$ malachite green (by weight) in water and $0.01 \%$ Tween 20. Phosphate concentrations were estimated using phosphate standard curve.

Modified anthrone assay. Total Rha content was estimated using a minor modification of the anthrone procedure. Reactions contained $0.08 \mathrm{~mL}$ of aqueous sample and water and $0.32 \mathrm{~mL}$ anthrone reagent $(0.2 \%$ anthrone in concentrated $\mathrm{H}_{2} \mathrm{SO}_{4}$ ). The samples were heated to $100^{\circ} \mathrm{C}, 10 \mathrm{~min}$, cooled in water (room temperature), and the absorbance at $580 \mathrm{~nm}$ was recorded. Rha concentrations were estimated using L-Rha standard curve.

Analysis of glycosyl composition by gas chromatography-mass spectrometry (GC-MS). Saccharide compositions were determined as either trimethylsilyl (TMS) derivatives of O-methyl glycosides, following methanolysis or as alditol acetates following hydrolysis with $2 \mathrm{~N}$ TFA and peracetylation, as described below ${ }^{88}$. Methanolic $\mathrm{HCl}(1 \mathrm{~N})$ was prepared by the careful dilution of the required amount of acetyl chloride into rapidly stirred, anhydrous methanol at $0{ }^{\circ} \mathrm{C}$. TMS-methyl glycoside samples contained $10 \mathrm{nmole}$ inositol as internal standard and were dried thoroughly from absolute ethanol ( 3 times), under dry nitrogen gas in glass $13 \times 100$ screw cap tubes with teflon-lined caps. Dried samples were dissolved in $0.2 \mathrm{~mL} 1 \mathrm{~N}$ methanolic $\mathrm{HCl}$ and heated to $100^{\circ} \mathrm{C}, 3 \mathrm{~h}$. Following methanolysis, samples were neutralized with $5-10 \mathrm{mg} \mathrm{AgCO}$ and re- $N$-acetylated with $0.1 \mathrm{~mL}$ acetic anhydride overnight. Re- $N$-acetylated methyl glycosides were recovered from the solid residue in $1 \mathrm{~mL}$ of methanol, dried thoroughly with toluene 2 times, to azeotrope the acetic anhydride, and trimethysilylated with $25 \mu \mathrm{L}$ TMS-HT (TCI America) at $80^{\circ} \mathrm{C}, 30 \mathrm{~min}$. TMS-methyl glycosides were dried briefly with addition of toluene under dry nitrogen gas, redissolved in $0.1 \mathrm{~mL}$ hexane and analyzed by gas chromatography/chemical ionization (methane) mass spectrometry on a Thermo Scientific Trace 1310 gas chromatograph, $0.25 \mathrm{~mm} \times 15 \mathrm{~m} \mathrm{DB}-1701$ (J\&W Scientific) capillary column, and an ISQ LT single quadrupole mass spectrometer in selective ionization mode (SIM) monitoring appropriate specific high molecular ions. Ion source temperature was $200^{\circ} \mathrm{C}$ and transfer line temperature was $240^{\circ} \mathrm{C}$ Samples $(1 \mu \mathrm{L}$ ) were injected in split mode (split flow $8 \mathrm{~mL} / \mathrm{min}$, split ratio $16: 1$ ) and chromatographed with $\mathrm{He}$ carrier gas $(0.5 \mathrm{~mL} / \mathrm{min})$ with a temperature program of $100^{\circ} \mathrm{C}$ for $1 \mathrm{~min}$, and $10^{\circ} \mathrm{C} / \mathrm{min}$ to $280^{\circ} \mathrm{C}$ with a final time of $2 \mathrm{~min}$ and detected in positive ion mode. The unknown TMS-sugars co-chromatographed with derivatives of authentic sugar standards and their respective full scan mass spectra contained $[\mathrm{MH}]^{+},[\mathrm{MH}-16]^{+},[\mathrm{MH}-32]^{+},[\mathrm{MH}-90]^{+},[\mathrm{MH}-122]^{+}$and $[\mathrm{MH}-180]^{+}$as the only high molecular weight ions. Specific ions for selective ion monitoring were: $\mathrm{TMS}_{3}-\mathrm{O}$-methyl-rhamnose $\left(\mathrm{M} / \mathrm{Z}=363[\mathrm{MH}-32]^{+}\right), \mathrm{TMS}_{4}{ }^{-O}-$ methyl-glucose $\left(\mathrm{M} / \mathrm{Z}=361[\mathrm{MH}-122]^{+}\right)$, $\mathrm{TMS}_{6}$-inositol $\left(\mathrm{M} / \mathrm{Z}=433[\mathrm{MH}-180]^{+}\right)$ and $\mathrm{TMS}_{3}-\mathrm{O}$-methyl-GlcNAc $\left(\mathrm{M} / \mathrm{Z}=420[\mathrm{MH}-32]^{+}\right)$.

Sodium borohydride-reduced, intact mild acid- or HONO-released polysaccharides, were fractionated by SEC on BioGel P150 and ion-exchange chromatography on DEAE-Toyopearl, and analyzed for reducing end sugars as alditol acetates. Polysaccharides were concentrated and desalted over Amicon Ultra-0.5, $3000 \mathrm{Da}$ cut-off, centrifugal filters, supplemented with $1 \mathrm{nmol}$ mannitol internal standard and hydrolyzed in $2 \mathrm{~N} \mathrm{TFA}, 120^{\circ} \mathrm{C}, 1 \mathrm{~h}$. Samples were dried under air with addition of 1-propanol 3 times and peracetylated with $0.2 \mathrm{~mL}$ pyridine/acetic anhydride $(1: 1), 100^{\circ} \mathrm{C}, 30 \mathrm{~min}$. Samples were diluted 
with $2 \mathrm{~mL} \mathrm{CHCl}_{3}$, partitioned with $2 \mathrm{~mL}$ water 3 times and dried under a stream of dry nitrogen gas with addition of toluene at room temperature. Alditol acetate analysis was carried out as described above for TMS-methyl glycosides except that the temperature program was $120^{\circ} \mathrm{C}, 1 \mathrm{~min}$, and $5^{\circ} \mathrm{C}$ per minute to $250^{\circ} \mathrm{C}$, with a final time of $2.5 \mathrm{~min}$. Full scan spectra of the alditol acetates contained $[\mathrm{MH}-60]^{+}$as the only high molecular weight ion detected. Chromatograms were prepared by selected ion monitoring using: $\mathrm{Ac}_{4}-2,5$-anhydromannitol $(\mathrm{M} /$ $\left.\mathrm{Z}=273[\mathrm{MH}-60]^{+}\right), \mathrm{Ac}_{6}$-mannitol $\left(\mathrm{M} / \mathrm{Z}=375[\mathrm{MH}-60]^{+}\right)$and $\mathrm{Ac}_{6}$-GlcNAcitol $\left(\mathrm{M} / \mathrm{Z}=374[\mathrm{MH}-60]^{+}\right)$.

Quantities of component sugars were calculated from GC areas after normalization to the internal standard and response factor corrections. Response factors were calculated from standard mixtures of sugars and internal standard using the formula: $\mathrm{Rf}=\left(\mathrm{A}_{\mathrm{x}} / \mathrm{A}_{\mathrm{is}}\right) /\left(\mathrm{C}_{\mathrm{x}} / \mathrm{C}_{\mathrm{is}}\right)$ in which, $\mathrm{A}_{\mathrm{x}}$ is $\mathrm{GC}$ area of analyte, $\mathrm{A}_{\mathrm{is}}$ is GC area of internal standard, $C_{x}$ is amount of analyte and $C_{i s}$ is amount of internal standard. Amounts of sugars were calculated using the formula: $\mathrm{C}_{\mathrm{x}}=\mathrm{C}_{\mathrm{is}} \times\left(\mathrm{A}_{\mathrm{x}} /\right.$ $A_{\text {is }}$ / Rf. In this analysis, an exponential increase in response factor associated with increasing amounts of analyte relative to internal standard was observed. To correct for this change in response factor, standard curves of increasing amounts of analytes to a constant quantity of internal standard were prepared and used to estimate the appropriate response factor.

NMR spectroscopy. Cell wall isolated from GAS 5005 was used for purification of GAC for NMR analysis ${ }^{15}$. NMR experiments on the GAC polysaccharide, $\sim 7 \mathrm{mg}$ in $\mathrm{D}_{2} \mathrm{O}(99.96 \%) \mathrm{pD} \sim 8$, were acquired at $323.2 \mathrm{~K}$ unless otherwise stated using the following Bruker spectrometers: AVANCE III $700 \mathrm{MHz}$ equipped with a $5 \mathrm{~mm}$ TCI Z-Gradient Cryoprobe $\left({ }^{1} \mathrm{H} /{ }^{13} \mathrm{C} /{ }^{15} \mathrm{~N}\right)$, AVANCE III $600 \mathrm{MHz}$ equipped with a $5 \mathrm{~mm}$ TXI inverse Z-Gradient probe $\left({ }^{1} \mathrm{H} /{ }^{31} \mathrm{P} /{ }^{13} \mathrm{C}\right.$ ), Avance III HD $800 \mathrm{MHz}$ equipped with a $3 \mathrm{~mm}$ TCI cryoprobe and an Avance III HD $600 \mathrm{MHz}$ equipped with a $5 \mathrm{~mm}$ BBI probe. Chemical shifts are reported in ppm using internal sodium 3-trimethylsilyl-(2,2,3,3- $\left.{ }^{2} \mathrm{H}_{4}\right)$-propanoate (TSP, $\delta_{\mathrm{H}} 0.00 \mathrm{ppm}$ ), external 1,4-dioxane in $\mathrm{D}_{2} \mathrm{O}\left(\delta_{\mathrm{C}} 67.40 \mathrm{ppm}\right)$ and $2 \% \mathrm{H}_{3} \mathrm{PO}_{4}$ in $\mathrm{D}_{2} \mathrm{O}\left(\delta_{\mathrm{P}} 0.00 \mathrm{ppm}\right)$ as references.

${ }^{1} \mathrm{H},{ }^{1} \mathrm{H}$-TOCSY NMR experiments were recorded with mixing times of 10,30 , 60,90 , and $120 \mathrm{~ms} .{ }^{1} \mathrm{H},{ }^{1} \mathrm{H}$-NOESY experiments ${ }^{89}$ were collected with mixing times of 100 and $200 \mathrm{~ms}$ at $700 \mathrm{MHz}$ and at $800 \mathrm{MHz}$. Multiplicity-edited ${ }^{1} \mathrm{H},{ }^{13} \mathrm{C}$-HSQC experiments ${ }^{90}$ were carried out with an echo/antiecho-TPPI gradient selection with and without decoupling during the acquisition. ${ }^{1} \mathrm{H},{ }^{13} \mathrm{C}$ HSQC-TOCSY experiments were acquired using the MLEV17 sequence for homonuclear Hartman-Hahn mixing with durations of 20, 40, 80, and $120 \mathrm{~ms}$, an echo/antiecho-TPPI gradient selection and heteronuclear decoupling during acquisition. The ${ }^{1} \mathrm{H},{ }^{13} \mathrm{C}$-HMBC experiment with a three-fold low-pass J-filter to suppress one-bond correlations and a band-selective ${ }^{1} \mathrm{H},{ }^{13} \mathrm{C}-\mathrm{CT}$-HMBC were run with a nominal long-range $J$ value of $8 \mathrm{~Hz} .{ }^{1} \mathrm{H},{ }^{31} \mathrm{P}$-Hetero-TOCSY experiments ${ }^{27}$ were collected using a DIPSI2 sequence with mixing times of 50 and $80 \mathrm{~ms}$. ${ }^{1} \mathrm{H},{ }^{31} \mathrm{P}-\mathrm{HMBC}$ experiments were recorded using an echo/antiecho gradient selection using 25, 50, and $90 \mathrm{~ms}$ delays for $J$ evolution, $8 \mathrm{k}$ and 512 points in the $F_{2}$ and $F_{1}$ dimensions, respectively, a nominal value for long-range ${ }^{n} J_{C H}$ of $8 \mathrm{~Hz}$. The $3 \mathrm{D}{ }^{1} \mathrm{H},{ }^{13} \mathrm{C},{ }^{31} \mathrm{P}^{91}$ spectra were obtained using echo/anti-echo gradient selection and constant time in $t_{2}$ with a nominal value of ${ }^{\mathrm{n}} J_{\mathrm{CP}}$ of $5 \mathrm{~Hz}$ and without multiplicity selection.

Non-uniform sampling (NUS) was employed for sparse sampling of 2D NMR experiments with a $50 \%$ or $25 \%$ coverage, thereby facilitating an increase in the number of increments in the indirect dimension by a factor of 2 or 4 , respectively, with overall equal measurement time. The Multi-Dimensional Decomposition $(\text { MDD-NMR })^{92-94}$ algorithm was employed to reconstruct the FIDs. The spectra were acquired using TopSpin 3.1 software (Bruker BioSpin) for the $600 \mathrm{MHz}$ spectrometer and TopSpin 3.2 (Bruker BioSpin) for the $700 \mathrm{MHz}$ spectrometer. Additional NMR spectra acquired at the Swedish NMR Centre used TopSpin 3.5 pl7 software (Bruker BioSpin) for the $600 \mathrm{MHz}$ spectrometer and TopSpin 3.6.2 (Bruker BioSpin) for the $800 \mathrm{MHz}$ spectrometer. The spectra were processed and analyzed using TopSpin 4.0.1 software (Bruker BioSpin).

Statistical analysis. Unless otherwise indicated, statistical analysis was carried out on pooled data from at least three independent biological repeats. Statistical analyses were performed using Graph Pad Prism version 9.2.0. Quantitative data were analyzed using either one-way or two-way ANOVA with either Tukey's or Bonferroni multiple comparison test. Symbols and error bars represent the mean and S.D., respectively. A $p$-value equal to or less than 0.05 was considered statistically significant.

Reporting summary. Further information on research design is available in the Nature Research Reporting Summary linked to this article.

\section{Data availability}

Atomic coordinates and structure factors of PplD crystal structure generated in this study have been deposited in the Protein Data Bank under accession code 6DQ3. All data generated during this study are included in the article and Supplementary information files. Source data are provided with this paper.
Received: 9 September 2021; Accepted: 7 January 2022;

Published online: 01 February 2022

\section{References}

1. Mistou, M. Y., Sutcliffe, I. C. \& van Sorge, N. M. Bacterial glycobiology: rhamnose-containing cell wall polysaccharides in Gram-positive bacteria. FEMS Microbiol. Rev. 40, 464-479 (2016).

2. Brown, S., Santa Maria, J. P. Jr. \& Walker, S. Wall teichoic acids of Grampositive bacteria. Annu Rev. Microbiol. 67, 313-336 (2013).

3. Denapaite, D., Bruckner, R., Hakenbeck, R. \& Vollmer, W. Biosynthesis of teichoic acids in Streptococcus pneumoniae and closely related species: lessons from genomes. Microb. Drug Resist. 18, 344-358 (2012).

4. Dale, J. B. et al. in Streptococcus pyogenes: Basic Biology to Clinical Manifestations (eds Ferretti, J. J., Stevens, D. L. \& Fischetti, V. A.) (2016).

5. Huang, D. H., Rama Krishna, N. \& Pritchard, D. G. Characterization of the group A streptococcal polysaccharide by two-dimensional ${ }^{1} \mathrm{H}$-nuclearmagnetic-resonance spectroscopy. Carbohydr. Res. 155, 193-199 (1986).

6. Kabanova, A. et al. Evaluation of a Group A Streptococcus synthetic oligosaccharide as vaccine candidate. Vaccine 29, 104-114 (2010).

7. Sabharwal, H. et al. Group A streptococcus (GAS) carbohydrate as an immunogen for protection against GAS infection. J. Infect. Dis. 193, 129-135 (2006)

8. van Sorge, N. M. et al. The classical Lancefield antigen of Group A Streptococcus is a virulence determinant with implications for vaccine design. Cell Host Microbe 15, 729-740 (2014).

9. Di Benedetto, R. et al. Rational design of a glycoconjugate vaccine against Group A Streptococcus. Int. J. Mol. Sci. 21, 8558 (2020).

10. Wang, S. et al. Group A Streptococcus cell wall oligosaccharide-streptococcal C5a peptidase conjugates as effective antibacterial vaccines. ACS Infect. Dis. 6 , 281-290 (2020).

11. Khatun, F. et al. Immunogenicity assessment of cell wall carbohydrates of Group A Streptococcus via self-adjuvanted glyco-lipopeptides. ACS Infect. Dis. 7, 390-405 (2021)

12. van der Beek, S. L. et al. GacA is essential for Group A Streptococcus and defines a new class of monomeric dTDP-4-dehydrorhamnose reductases (RmlD). Mol. Microbiol. 98, 946-962 (2015).

13. Rush, J. S. et al. The molecular mechanism of $\mathrm{N}$-acetylglucosamine side-chain attachment to the Lancefield group A carbohydrate in Streptococcus pyogenes. J. Biol. Chem. 292, 19441-19457 (2017)

14. van der Beek, S. L. et al. Streptococcal dTDP-L-rhamnose biosynthesis enzymes: functional characterization and lead compound identification. Mol. Microbiol. 111, 951-964 (2019)

15. Edgar, R. J. et al. Discovery of glycerol phosphate modification on streptococcal rhamnose polysaccharides. Nat. Chem. Biol. 15, 463-471 (2019)

16. Zorzoli, A. et al. Group A, B, C, and G Streptococcus Lancefield antigen biosynthesis is initiated by a conserved alpha-d-GlcNAc-beta-1,4-1rhamnosyltransferase. J. Biol. Chem. 294, 15237-15256 (2019).

17. Soldo, B., Lazarevic, V. \& Karamata, D. tagO is involved in the synthesis of all anionic cell-wall polymers in Bacillus subtilis 168. Microbiology 148, 2079-2087 (2002)

18. Schaefer, K., Matano, L. M., Qiao, Y., Kahne, D. \& Walker, S. In vitro reconstitution demonstrates the cell wall ligase activity of LCP proteins. Nat Chem. Biol. 13, 396-401 (2017).

19. Leloir, L. F. \& Cardini, C. E. in Comprehensive Biochemistry: Carbohydrates Vol. 5 (eds Florkin, M. \& Stotz, E. H.) Ch. IV, 113-140 (Elsevier Publishing Company, 1963).

20. Kojima, N., Araki, Y. \& Ito, E. Structural studies on the linkage unit of ribito teichoic acid of Lactobacillus plantarum. Eur. J. Biochem 148, 29-34 (1985).

21. Walter, A. et al. Phosphoglycerol-type wall and lipoteichoic acids are enantiomeric polymers differentiated by the stereospecific glycerophosphodiesterase GlpQ. J. Biol. Chem. 295, 4024-4034 (2020).

22. Dmitriev, D. A., Knirel, Y. A. \& Kochetkov, N. K. Selective cleavage of glycosidic linkages: studies with the model compound benzyl 2-acetamido-2 deoxy-3-O- $\beta$-D-galactopyranosyl- $\alpha-\mathrm{D}$-glucopyranoside. Carbohydr. Res. 29, 451-457 (1973).

23. Lundberg, J. O., Weitzberg, E. \& Gladwin, M. T. The nitrate-nitrite-nitric oxide pathway in physiology and therapeutics. Nat. Rev. Drug Discov. 7, 156-167 (2008)

24. Erbing, C., Lindberg, B. \& Svensson, S. Deamination of methyl 2-amino-2 deoxy-alpha-and -beta-D-glycopyranosides. Acta Chem. Scandinavica 27 3699-3704 (1973).

25. Zamakhaeva, S. et al. Modification of cell wall polysaccharide guides cell division in Streptococcus mutans. Nat. Chem. Biol. 17, 878-887 (2021).

26. Widmalm, G. in Comprehensive Glycoscience Vol. 1 (ed Barchi, J. J. Jr.) 340-373 (Elsevier, 2021). 
27. Kellogg, G. W. Proton-detected hetero-TOCSY experiments with application to nucleic acids. J. Magn. Reson. 98, 176-182 (1992).

28. Lundborg, M. \& Widmalm, G. Structural analysis of glycans by NMR chemical shift prediction. Anal. Chem. 83, 1514-1517 (2011).

29. Olsson, U., Lycknert, K., Stenutz, R., Weintraub, A. \& Widmalm, G. Structural analysis of the O-antigen polysaccharide from Escherichia coli O152. Carbohydr. Res. 340, 167-171 (2005).

30. Meroueh, S. O. et al. Three-dimensional structure of the bacterial cell wall peptidoglycan. Proc. Natl Acad. Sci. USA 103, 4404-4409 (2006).

31. Zahringer, $U$. et al. NMR-based structural analysis of the complete rough-type lipopolysaccharide isolated from Capnocytophaga canimorsus. J. Biol. Chem. 289, 23963-23976 (2014).

32. Zahringer, U. et al. NMR-based structural analysis of the complete rough-type lipopolysaccharide isolated from Capnocytophaga canimorsus. J. Biol. Chem. 290, 25273 (2015).

33. Nawaji, M., Izawa, H., Kaneko, Y. \& Kadokawa, J. Enzymatic alphaglucosaminylation of maltooligosaccharides catalyzed by phosphorylase. Carbohydr. Res. 343, 2692-2696 (2008).

34. Beecher, C. N. \& Larive, C. K. (1)H and (15)N NMR Characterization of the Amine Groups of Heparan Sulfate Related Glucosamine Monosaccharides in Aqueous Solution. Anal. Chem. 87, 6842-6848 (2015).

35. Virues, C. et al. Formulation of anomerization and protonation in dglucosamine, based on (1)H NMR. Carbohydr. Res. 490, 107952 (2020).

36. Jansson, P. E., Kenne, L. \& Widmalm, G. Computer-assisted structural analysis of polysaccharides with an extended version of CASPER using $1 \mathrm{H}$ and 13C-n.m.r. data. Carbohydr. Res. 188, 169-191 (1989).

37. Söderman, P., Jansson, P. E. \& Widmalm, G. Synthesis, NMR spectroscopy and conformational studies of the four anomeric methyl glycosides of the trisaccharide D-Glcp-( $\rightarrow 3)$-[D-Glcp-( $1 \rightarrow 4)]-\alpha-D-G l c p$. J. Chem. Soc. Perkin Trans. 2, 639-648 (1998).

38. Gautam, S., Kim, T., Lester, E., Deep, D. \& Spiegel, D. A. Wall teichoic acids prevent antibody binding to epitopes within the cell wall of Staphylococcus aureus. ACS Chem. Biol. 11, 25-30 (2016).

39. Eckert, C., Lecerf, M., Dubost, L., Arthur, M. \& Mesnage, S. Functional analysis of AtlA, the major $\mathrm{N}$-acetylglucosaminidase of Enterococcus faecalis. J. Bacteriol. 188, 8513-8519 (2006).

40. Stinemetz, E. K. et al. Processing of the major autolysin of E. faecalis, AtlA, by the zinc-metalloprotease, GelE, impacts AtlA septal localization and cell separation. PLoS ONE 12, e0186706 (2017)

41. Mesnage, S. et al. Molecular basis for bacterial peptidoglycan recognition by LysM domains. Nat. Commun. 5, 4269 (2014).

42. Vollmer, W. \& Tomasz, A. The pgdA gene encodes for a peptidoglycan $\mathrm{N}$-acetylglucosamine deacetylase in Streptococcus pneumoniae. J. Biol. Chem. 275, 20496-20501 (2000).

43. Milani, C. J. et al. The novel polysaccharide deacetylase homologue Pdi contributes to virulence of the aquatic pathogen Streptococcus iniae. Microbiology 156, 543-554 (2010).

44. Krissinel, E. \& Henrick, K. Inference of macromolecular assemblies from crystalline state. J. Mol. Biol. 372, 774-797 (2007).

45. Blair, D. E., Schuttelkopf, A. W., MacRae, J. I. \& van Aalten, D. M. Structure and metal-dependent mechanism of peptidoglycan deacetylase, a streptococcal virulence factor. Proc. Natl Acad. Sci. USA 102, 15429-15434 (2005).

46. Little, D. J. et al. The structure- and metal-dependent activity of Escherichia coli PgaB provides insight into the partial de- $\mathrm{N}$-acetylation of poly-beta-1,6$\mathrm{N}$-acetyl-D-glucosamine. J. Biol. Chem. 287, 31126-31137 (2012).

47. Little, D. J. et al. Structural basis for the De-N-acetylation of Poly-beta-1,6-Nacetyl-D-glucosamine in Gram-positive bacteria. J. Biol. Chem. 289, 35907-35917 (2014).

48. Boneca, I. G. et al. A critical role for peptidoglycan N-deacetylation in Listeria evasion from the host innate immune system. Proc. Natl Acad. Sci. USA 104, 997-1002 (2007).

49. Wang, G. et al. Peptidoglycan deacetylation in Helicobacter pylori contributes to bacterial survival by mitigating host immune responses. Infect. Immun. 78, 4660-4666 (2010).

50. Kaoukab-Raji, A., Biskri, L., Bernardini, M. L. \& Allaoui, A. Characterization of SfPgdA, a Shigella flexneri peptidoglycan deacetylase required for bacterial persistence within polymorphonuclear neutrophils. Microbes Infect. 14, 619-627 (2012).

51. Chipman, D. M., Grisaro, V. \& Sharon, N. The binding of oligosaccharides containing $\mathrm{N}$-acetylglucosamine and $\mathrm{N}$-acetylmuramic acid to lysozyme. The specificity of binding subsites. J. Biol. Chem. 242, 4388-4394 (1967).

52. Ragland, S. A. \& Criss, A. K. From bacterial killing to immune modulation: Recent insights into the functions of lysozyme. PLoS Pathog. 13, e1006512 (2017).

53. Band, V. I. \& Weiss, D. S. Mechanisms of antimicrobial peptide resistance in Gram-negative bacteria. Antibiotics 4, 18-41 (2015).

54. Micoli, F. et al. Glycoconjugate vaccines: current approaches towards faster vaccine design. Expert Rev. Vaccines 18, 881-895 (2019).
55. Pokrovskaya, V. et al. Functional characterization of Staphylococcus epidermidis IcaB, a de- $\mathrm{N}$-acetylase important for biofilm formation. Biochemistry 52, 5463-5471 (2013).

56. Aragunde, H., Biarnes, X. \& Planas, A. Substrate recognition and specificity of chitin deacetylases and related family 4 carbohydrate esterases. Int. J. Mol. Sci. 19, 412 (2018).

57. Shiva, S. et al. Ceruloplasmin is a NO oxidase and nitrite synthase that determines endocrine NO homeostasis. Nat. Chem. Biol. 2, 486-493 (2006).

58. Lundberg, J. O., Weitzberg, E., Cole, J. A. \& Benjamin, N. Nitrate, bacteria and human health. Nat. Rev. Microbiol. 2, 593-602 (2004).

59. Khor, B. et al. Interconnections between the oral and gut microbiomes: reversal of microbial dysbiosis and the balance between systemic health and disease. Microorganisms 9, 496 (2021).

60. Wang, G. Human antimicrobial peptides and proteins. Pharmaceuticals 7 , 545-594 (2014)

61. Buckland, A. G. \& Wilton, D. C. Inhibition of secreted phospholipases A2 by annexin V. Competition for anionic phospholipid interfaces allows an assessment of the relative interfacial affinities of secreted phospholipases A2. Biochim. Biophys. Acta 1391, 367-376 (1998).

62. Hsu, Y. H., Dumlao, D. S., Cao, J. \& Dennis, E. A. Assessing phospholipase A2 activity toward cardiolipin by mass spectrometry. PLoS ONE 8, e59267 (2013).

63. Koprivnjak, T., Peschel, A., Gelb, M. H., Liang, N. S. \& Weiss, J. P. Role of charge properties of bacterial envelope in bactericidal action of human group IIA phospholipase A2 against Staphylococcus aureus. J. Biol. Chem. 277, 47636-47644 (2002).

64. Gronroos, J. O., Salonen, J. H., Viander, M., Nevalainen, T. J. \& Laine, V. J. Roles of group IIA phospholipase A2 and complement in killing of bacteria by acute phase serum. Scand. J. Immunol. 62, 413-419 (2005).

65. Movert, E. et al. Secreted group IIA phospholipase A2 protects humans against the group B streptococcus: experimental and clinical evidence. J. Infect. Dis. 208, 2025-2035 (2013).

66. Movert, E., Wu, Y., Lambeau, G., Touqui, L. \& Areschoug, T. A novel bacterial resistance mechanism against human group IIA-secreted phospholipase A2: role of Streptococcus pyogenes sortase A. J. Immunol. 187, 6437-6446 (2011).

67. Parseghian, M. H. \& Luhrs, K. A. Beyond the walls of the nucleus: the role of histones in cellular signaling and innate immunity. Biochem. Cell Biol. 84, 589-604 (2006).

68. Derde, M. et al. Hen egg white lysozyme permeabilizes Escherichia coli outer and inner membranes. J. Agric. food Chem. 61, 9922-9929 (2013).

69. Weiss, J. P. Molecular determinants of bacterial sensitivity and resistance to mammalian Group IIA phospholipase A2. Biochim Biophys. Acta 1848, 3072-3077 (2015)

70. Dore, E. \& Boilard, E. Roles of secreted phospholipase A2 group IIA in inflammation and host defense. Biochim. Biophys. Acta Mol. Cell Biol. Lipids 1864, 789-802 (2019)

71. van Hensbergen, V. P., Wu, Y., van Sorge, N. M. \& Touqui, L. Type IIA secreted phospholipase A2 in host defense against bacterial infections. Trends Immunol. 41, 313-326 (2020).

72. Hunt, C. L., Nauseef, W. M. \& Weiss, J. P. Effect of D-alanylation of (lipo) teichoic acids of Staphylococcus aureus on host secretory phospholipase A2 action before and after phagocytosis by human neutrophils. J. Immunol. 176, 4987-4994 (2006)

73. Herbert, S. et al. Molecular basis of resistance to muramidase and cationic antimicrobial peptide activity of lysozyme in staphylococci. PLoS Pathog. 3, e102 (2007).

74. Dohrmann, S. et al. Group A Streptococcal M1 protein provides resistance against the antimicrobial activity of histones. Sci. Rep. 7, 43039 (2017)

75. van Hensbergen, V. P. et al. Streptococcal Lancefield polysaccharides are critical cell wall determinants for human Group IIA secreted phospholipase A2 to exert its bactericidal effects. PLoS Pathog. 14, e1007348 (2018).

76. Mashburn-Warren, L., Morrison, D. A. \& Federle, M. J. A novel doubletryptophan peptide pheromone controls competence in Streptococcus spp. via an Rgg regulator. Mol. Microbiol. 78, 589-606 (2010).

77. Le Breton, Y. \& McIver, K. S. Genetic manipulation of Streptococcus pyogenes (the Group A Streptococcus, GAS). Curr. Protoc. Microbiol. 30, Unit 9D 3 (2013).

78. Gogos, A., Jimenez, J. C., Chang, J. C., Wilkening, R. V. \& Federle, M. J. A quorum sensing-regulated protein binds cell wall components and enhances lysozyme resistance in Streptococcus pyogenes. J. Bacteriol. 200, e00701-17. (2018).

79. Kabsch, W. Xds. Acta Crystallogr. Sect. D. Biol. Crystallogr. 66, 125-132 (2010).

80. McCoy, A. J. et al. Phaser crystallographic software. J. Appl. Crystallogr. 40, 658-674 (2007).

81. Sheldrick, G. M. A short history of SHELX. Acta Crystallogr. A 64, 112-122 (2008).

82. Cowtan, K. Recent developments in classical density modification. Acta Crystallogr. D. Biol. Crystallogr. 66, 470-478 (2010). 
83. Cowtan, K. The Buccaneer software for automated model building. 1. Tracing protein chains. Acta Crystallogr. D. Biol. Crystallogr. 62, 1002-1011 (2006).

84. Emsley, P., Lohkamp, B., Scott, W. G. \& Cowtan, K. Features and development of Coot. Acta Crystallogr. Sect. D. Biol. Crystallogr. 66, 486-501 (2010).

85. Afonine, P. V. et al. Towards automated crystallographic structure refinement with phenix.refine. Acta Crystallogr. Sect. D. Biol. Crystallogr. 68, 352-367 (2012).

86. Ghomashchi, F. et al. Preparation of the full set of recombinant mouse- and human-secreted phospholipases A2. Methods Enzymol. 583, 35-69 (2017).

87. Bui, N. K. et al. Isolation and analysis of cell wall components from Streptococcus pneumoniae. Anal. Biochem. 421, 657-666 (2012).

88. York, W. S., Darvill, A. G., McNeil, M., Stevenson, T. T. \& Albersheim, P. Isolation and characterization of plant cell walls and cell wall components. Methods Enzymol. 118, 3-40 (1986).

89. Wagner, R. \& Berger, S. Gradient-selected NOESY-A fourfold reduction of the measurement time for the NOESY Experiment. J. Magn. Reson. Ser. A 123, 119-121 (1996).

90. Willker, W., Leibfritz, D., Kerssebaum, R. \& Bermel, W. Gradient selection in inverse heteronuclear correlation spectroscopy. Magn. Reson. Chem. 31, 287-292 (1993).

91. Marino, J. P. et al. Three-dimensional triple-resonance ${ }^{1} \mathrm{H},{ }^{13} \mathrm{C},{ }^{31} \mathrm{P}$ experiment: sequential through-bond correlation of ribose protons and intervening phosphorus along the RNA oligonucleotide backbone. J. Am. Chem. Soc. 116, 6472-6473 (1994).

92. Orekhov, V. Y., Ibraghimov, I. \& Billeter, M. Optimizing resolution in multidimensional NMR by three-way decomposition. J. Biomol. NMR 27 165-173 (2003).

93. Tugarinov, V., Kay, L. E., Ibraghimov, I. \& Orekhov, V. Y. High-resolution four-dimensional ${ }^{1} \mathrm{H}-{ }^{13} \mathrm{C}$ NOE spectroscopy using methyl-TROSY, sparse data acquisition, and multidimensional decomposition. J. Am. Chem. Soc. 127, 2767-2775 (2005).

94. Jaravine, V., Ibraghimov, I. \& Orekhov, V. Y. Removal of a time barrier for high-resolution multidimensional NMR spectroscopy. Nat. Methods 3, 605-607 (2006).

95. Coligan, J. E., Kindt, T. J. \& Krause, R. M. Structure of the streptococcal groups A, A-variant and C carbohydrates. Immunochemistry 15, 755-760 (1978).

96. McCarty, M. Variation in the group-specific carbohydrate of group A streptococci. II. Studies on the chemical basis for serological specificity of the carbohydrates. J. Exp. Med. 104, 629-643 (1956).

\section{Acknowledgements}

The authors thank Dr. John F. Timoney (University of Kentucky) for providing S. equi, Dr. Jeffrey M. Bosken, and Dr. Edward D. Hall (University of Kentucky) for the use of the Thermo Fisher Scientific GC-Mass Spectrometer, Dr. Catalina Velez-Ortega (University of Kentucky) for the access to Leica SP8 confocal microscope, and Dr. Peter H. Spielmann (University of Kentucky) for helpful discussions. This work was supported by NIH grants R01 AI143690 from the NIAID and R01 DE028916 from the NIDCR and (to N.K.), the Swedish Research Council (no. 2017-03703) and The Knut and Alice Wallenberg Foundation (to G.W.). The Swedish NMR Centre at University of Gothenburg is acknowledged for support. Use of the Stanford Synchrotron Radiation Lightsource, SLAC
National Accelerator Laboratory, is supported by the U.S. Department of Energy, Office of Science, Office of Basic Energy Sciences under Contract No. DE-AC02-76SF00515. The SSRL Structural Molecular Biology Program is supported by the DOE Office of Biological and Environmental Research, and by the National Institutes of Health,

National Institute of General Medical Sciences (P30GM133894). The funders had no role in study design, data collection and interpretation, or the decision to submit the work for publication.

\section{Author contributions}

J.S.R., A.R., G.L., M.J.F., K.V.K., G.W., and N.K. designed the experiments. J.S.R., P.P., A.A.P., C.W.K., A.G., M.M.R., G.L., G.W., and N.K. performed functional and biochemical experiments. J.L. and K.V.K. carried out X-ray crystallography and structure analysis. A.R. and G.W. performed NMR studies. J.C.C., K.V.K. and N.K. constructed plasmids and isolated mutants. S.Z. performed microscopy analysis. J.S.R., A.R., K.V.K., G.W., and N.K. analyzed the data. N.K. wrote the manuscript with contributions from all authors. All authors reviewed the results and approved the final version of the manuscript.

\section{Competing interests}

The authors declare no competing interests.

\section{Additional information}

Supplementary information The online version contains supplementary material available at https://doi.org/10.1038/s41467-022-28257-0.

Correspondence and requests for materials should be addressed to Natalia Korotkova.

Peer review information Nature Communications thanks Alexander Eletsky, Francesca Micoli and the other, anonymous, reviewers for their contribution to the peer review of this work.

Reprints and permission information is available at http://www.nature.com/reprints

Publisher's note Springer Nature remains neutral with regard to jurisdictional claims in published maps and institutional affiliations.

Open Access This article is licensed under a Creative Commons Attribution 4.0 International License, which permits use, sharing, adaptation, distribution and reproduction in any medium or format, as long as you give appropriate credit to the original author(s) and the source, provide a link to the Creative Commons license, and indicate if changes were made. The images or other third party material in this article are included in the article's Creative Commons license, unless indicated otherwise in a credit line to the material. If material is not included in the article's Creative Commons license and your intended use is not permitted by statutory regulation or exceeds the permitted use, you will need to obtain permission directly from the copyright holder. To view a copy of this license, visit http://creativecommons.org/ licenses/by/4.0\%

(C) The Author(s) 2022 